Article

\title{
Designing with Pathways: A Spatial Design Approach for Adaptive and Sustainable Landscapes
}

\author{
Mark Zandvoort ${ }^{1, *} \mathbb{\infty}$, Nora Kooijmans ${ }^{1}$, Paul Kirshen ${ }^{2}$ and Adri van den Brink ${ }^{1}$ \\ 1 Landscape Architecture Chair Group, Environmental Sciences Department, Wageningen University, \\ Droevendaalsesteeg 3, 6708 PB Wageningen, The Netherlands; n.a.kooijmans@gmail.com (N.K.); \\ adri.vandenbrink@wur.nl (A.v.d.B.) \\ 2 Sustainable Solutions Lab, School for the Environment, University of Massachusetts, \\ Boston, MA 02125, USA; paul.kirshen@umb.edu \\ * Correspondence: mark.zandvoort@wur.nl; Tel.: +31-317-483322
}

Received: 30 November 2018; Accepted: 15 January 2019; Published: 22 January 2019

\begin{abstract}
Despite rising attention to pathways thinking in multiple domains such as climate adaptation, energy supply planning, and flood risk management, their spatial translation is so far understudied. We set out to study how spatial design based on pathways thinking can help develop more adaptive and sustainable landscapes. Using landscape analysis, field research, and research-through-designing in a case study on climate resilience in Boston (USA), we argue for better understanding of the spatial and design consequences of pathways in general. Our results indicate that pathways can be spatially translated, demanding landscape-informed choices when sequencing different policy actions. We found that spatial designing makes the landscape consequences of pathways transparent and enables policy-makers to replace the input of policy actions with spatial interventions, select pathways according to different underlying design strategies, use the mapped pathways to initiate an iterative research-through-designing process to test and inform different designs, and spatially visualize the pathways and possible sequences of actions. We conclude that policy-makers should be cognizant about the spatial implications of pathways and offer directions to enrich applications of pathways thinking for achieving adaptive and sustainable landscapes.
\end{abstract}

Keywords: adaptiveness; climate adaptation; decision pathways; flood risk management; landscape architecture; spatial design; uncertainty; visualization

\section{Introduction}

Attention to pathways thinking has rapidly expanded in recent years. In academic debate, pathways are described and proposed as a move towards adaptive policy-making [1]. Pathways, as a decision-oriented approach to map sequences of policy actions, shift policy-making away from the ambition of attempting to achieve static, predefined outcomes. Their general underlying assumption is that policy and planning should coevolve with changing conditions and, thus, can be better perceived as a sequence of actions taken over time, with particular emphasis on the first decision [2,3] and mapping scenarios to enable later adaptations to currently unknown future changes.

Despite the original intent of pathways, their spatial translation is so far understudied. Instead, recent research has focused on the participatory mapping of pathways [4], the development of policy design criteria [5], the management of transition pathways [6], determining policy boundaries [3], the role of place-based social framing as a boundary for pathways [7], the social trade-offs underlying pathways [8], and quantifying the flexibility offered by pathways through real option analysis [9-11]. Many policy actions in these studies have long-term implications for the spatial configuration of 
a location and its surrounding landscape. These implications are, however, often neglected [7], despite the influence of policy options (choices available to policy-makers) on landscapes and the spatial allocation of measures [12,13]. Therefore, policy-making based on pathways asks for anticipation of these spatial consequences for landscapes.

To gain insight into the spatial consequences of pathways, we turn to landscape architecture as a particular discipline. Landscape architecture connects landscape studies such as hydrology, soil sciences, and geography with insight in and knowledge about the planning, design, and management of landscapes [14,15]. Landscape architecture is forward-looking, has a particular set of design instruments, and acts as an intermediary between policy and design and the implementation of spatial measures [16]. Therefore, landscape architecture knowledge is ideally suited to study the spatial implications of pathways. In addition, pathways themselves might offer a valuable set of concepts to create new landscape design approaches that help shift away from landscape design aimed at static, predefined outcomes, towards creating adaptive and time-sensitive designs. More adaptiveness in design might ameliorate the negative consequences of uncertainty about future change [17].

Pathways can offer insight into spatial measures that enable landscapes to co-evolve with changing conditions, while simultaneously restructuring them to particular needs. Other approaches, such as robust decision-making or real options, focus on robust or flexible strategies for landscape change [11]. Here we focus on pathways because of their particular contribution to understanding long-term change. We assume that planners can decide on sustainable and adaptive policy options when the spatial consequences of pathways are transparent. Therefore, we set out to study how spatial designing based on pathways thinking can alter landscapes towards a more adaptive and sustainable organization. We aim to know what the spatial implications of pathways are to distill insights about the influence of landscape on the (in)adequacy of policy actions. This may inform policy-makers to set goals and determine portfolios of action specified through a landscape vocabulary and make pathways thinking more transparent as to their spatial implications. Based on this, we also study how pathways thinking can be used to inform landscape architects to design sustainable and adaptive landscapes. Our research question is the following: What contribution can pathways thinking offer spatial design to make landscapes more adaptive and sustainable?

In the next section we present our conceptual framework. Then, we outline our methods, which are based on a case study approach in which we used landscape analysis and research-through-designing on a case study in Boston, USA. In the next section we describe our results, outline the different spatial consequences of pathways and the landscape configurations that emerged to be decisive for spatial designs, and show how pathways can be used as a design heuristic for landscape architects. Following this, we discuss our results based on the current academic debate about pathways thinking and landscape studies. Lastly, we synthesize our insights and offer the reader our conclusions for the wider field of pathways thinking and their spatial consequences in general, with particular emphasis on the methodological use of landscape architecture when applying pathways across domains.

\section{Conceptual Framework}

Our conceptual framework is based on contemporary thinking about pathways and the underlying scientific concepts of uncertainty and adaptiveness. We connect this realm of thought about pathways to state-of-the-art landscape architecture knowledge about landscape interventions and transformations. Following this, we relate these combined bodies of knowledge to design challenges which policy-makers are confronted with when deciding on and designing for long-term interventions in landscapes.

\subsection{Pathways, Uncertainty, and Adaptiveness}

Pathways are strongly embedded in policy-making for climate adaptation and water management [18-20], adaptiveness in environmental-planning-related sciences [21,22], and transition management [3]. These domains all clearly have a spatial component. Moreover, they all signal or 
start from the assumption of a nonstatic world. Nonstatic change is abrupt, involves irreducible uncertainty, and has far-reaching consequences for spatial measures. This means that models cannot predict the future with a high level of accuracy and, as a result, policy-makers gain limited insight into the potential impact of future change on a specific location or the adequacy of policy options.

Moreover, as Wise et al. [3] argue, societal responses to change are constrained by vested interests and path dependencies, for which a broader conceptualization of pathways is required. A set of these path dependencies is present in the landscape: existing infrastructures, geography, and the built environment are all physically binding spatial interventions [23]. Additionally, human artifacts in the landscape reflect past values and interests [24]. Landscapes can therefore not be transformed easily and show inert properties [25], while a desire for adaptiveness challenges this status quo embedded in the landscape [26].

Pathways thinking is based on the concept of adaptiveness, which informs adaptive approaches to handle uncertainty. In particular, pathways relate to irreducible uncertainty for which no clear probabilistic information exists (e.g., [1]). While models are used in adaptive approaches, they are not used as prediction tools as is done in predict-then-adapt decision frameworks [18]. Instead, they are used as scenario generators, sources of insight into complex system behavior, and aids to critical thinking [27]. Adaptive approaches to planning and decision-making show that accurate and precise predictions are not a prerequisite for anticipatory adaptation and instead build on the idea that even if the future is unknown, the unknown is not unmanageable [28]. This points us to landscape architecture as a discipline heavily involved in the planning and management of landscapes.

\subsection{Landscape Architecture: Design for Spatial Interventions}

The assumption of pathways thinking for a nonlinear and unpredictable world contrasts with traditional landscape architecture, in which design presupposes the ability of a designer to control all parts of the design [29]. Within the field of landscape architecture, situations of uncertainty create contradiction, because, despite the will to create a predetermined future configuration that is calculated, tested, and offers certainty, there is also the acknowledgement that complex systems "do not allow precise prediction of specific events or outcomes of interventions" [30] (p. 31). Moroni [31], emphasizing the importance of this understanding, concludes that " $[t]$ aking the marked complexity of the city seriously would entail profound revision of not only the way in which we interpret it but also of how we intervene in its regulation". In other words, he argues that the way we see our surroundings changes the way we treat it. Here, we argue that it would not only change how we treat our surroundings, but also the way in which we intervene in its regulation through design. Thus, in the phrasing of van Dijk [13] (p. 124), we need a deeper understanding about "how design co-constitutes what is, and thus influences what will be".

The design of measures such as roads, dikes, dams, urban neighborhoods, etc., involves both the aesthetic and functional properties of interventions. Landscape architecture is particularly focused on designing for measures in relation to larger spatial scales such as neighborhoods, infrastructure, or other large-scale elements in the landscape. Based on the assumption of uncertainty and nonlinearity, landscape architects have to accept that there is always a gap between the desired, the intended, and the actual results of their design, and this gap cannot be removed by improved knowledge or information. Therefore, designers should focus on developing more innovative approaches for design under uncertainty in order to improve spatial development and adjust current practices to better adapt to future change and related uncertainties. Adaptiveness and pathways thinking might offer an inspiring direction to do so.

\subsection{Relating Adaptive Pathways to Spatial Design}

We start here from the notion that pathways still pose a landscape design challenge when they are translated into decision support for spatially allocated measures, which most policy options are. Two examples help support this claim. When pathways are used to envision a trajectory in which 
particular industries shift to hydrogen-based energy provision, such as initiated for the Swedish iron and steel industry, a different energy landscape is needed (e.g., [6,32]). Or, when envisioning pathways for a large artificial lake, such as the IJsselmeer in the Netherlands, creating a flexible water regime involves very different landscape choices and consequences compared to installing pumps or a gradual increase in water levels (e.g., [5,20]).

Envisioning different developmental trajectories over time and mapping the possibilities to alter their course over time is the core to pathways thinking. To translate this into a design challenge, we start from the essential unpredictability of future change. Our design challenge is to achieve an adaptive design that is sensitive to uncertainty and the unfolding trajectory of paths over time. Conceptually, this leads to a design challenge for which an adaptive strategy based on pathways might be feasible.

We see the design challenge underlying pathways as a demand for a strategy that can help designers to find ways to adapt spatial configurations in a later phase, if the future turns out to be different than expected, or to make explicit choices about path dependency when proposing more irreversible measures. An adaptive strategy, however, favors adaptation measures that are reversible, removable, adjustable, and/or upgradable if future change makes them insufficient. From a landscape perspective, such flexibility can best be built into the structure. With the built-in possibility of a future upgrade or adjustment, large potential regrets associated with either overinvestment or underinvestment in adaptation measures can be avoided [33]. This strategy supports design based on short-term measures, while keeping options for other measures open on the longer term. Measures that supplement each other are favored so that they can be added to each other over time to work together as a larger system that can keep growing along with changes in the environment. Pathways are used as input for the development of a spatial design for a specific site. An example is the possible progression of a temporary flood barrier towards a permanent floodable park through a trajectory of changes, making up just one path and conceptually depicted in Figure 1. A pathways map comprises multiple development trajectories between which shifts can occur or are deliberately made at different times depending on how the future evolves.
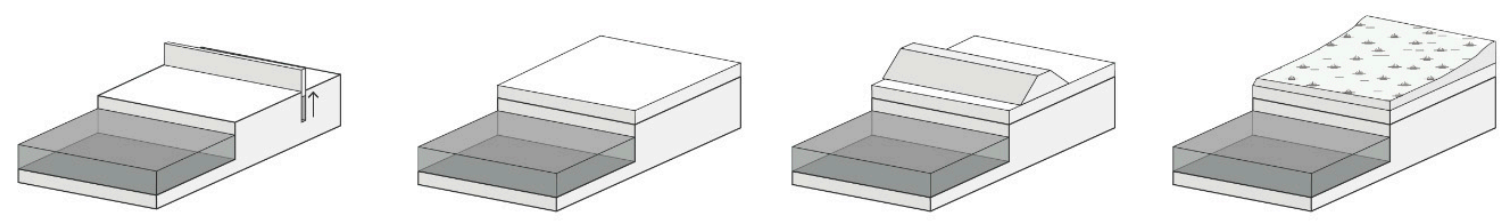

Figure 1. Conceptual depiction of a development trajectory with as first measure a temporary flood barrier, progressing to locally raising the area and the later addition of a dike, ending in a permanently floodable park. Source: Authors.

Design choices depend on particular goals, stakeholder preferences, and the current organization of the landscape. Landscape architects can show the benefits of spatially visualizing current possibilities for measures (options or optional measures) and related sequences of spatial adaptation measures. In the next section we outline how we have done so in a case study in Boston.

\section{Methods and Materials}

Important from a landscape perspective is the actual condensation of possible measures to site-specific preferences and design. To study this, we took a two-step approach based on a case study. First, pathways were created on a conceptual level to address what the goals and possible measures are, based on the method in reference [20]. This was complemented with a landscape analysis [15] to query the effects of different measures for the area and to spatially fit them into the existing landscape on a general level. After this exploratory phase, our second step consisted of focusing on the spatial implications of the pathways through an iterative design process in which multiple trajectories were provoked to determine the specifics of their spatial effects. Our method to focus on these landscape 
effects was research-through-designing [34,35]. Below, we describe the selection criteria for our case study, the landscape analysis, and our use of research-through-designing.

\subsection{Case Study}

Our research design was based on a single case study. Case study methodology allows researchers to develop emergent theory through allowing a high information density and the exploration of sensitive issues such as a detailed analysis of the implications of pathways for existing landscapes, and vice versa [36]. The in-depth study of such effects allows for the development of theory about the influence of landscape on policy options and spatial measures and their sequencing in pathways or trajectories of future change based on tipping points [20]. However, the specific findings of a case do not allow for generalization as such because of their context dependency [37]. Nevertheless, a paradigmatic case can help explore and draw conclusions on the relationship between pathways, trajectories of change, and landscape architecture and spatial design.

We selected the Bostonian initiative of enhancing the climate resilience of East Boston as a paradigmatic case. We chose to focus on climate resilience because climate change is a prevalent threat to many areas in the world, has clear spatial impacts regarding risk and climate adaptation measures, and is still surrounded by uncertainty as to the speed and extent of local impacts in the middle to long term. We chose the area of East Boston, located within the city of Boston (USA), because it offers a prototype of a densely urbanized coastal area that has a high vulnerability and exposure to flood risk. Moreover, the World Bank ranked Boston the eighth highest metropolitan area worldwide in expected annual economic losses (\$237 million) due to coastal flooding [38]. Another reason to select East Boston is that the area is long established, which offers the opportunity to include past and current choices in the area's configuration in the landscape analysis. The combined effects of climate change with expansion and densification represent a situation that has general relevance for many coastal cities, even though not all cities are as highly organized as Boston. The reported outcomes are part of a larger study on climate change adaptation in East Boston. Douglas et al. [39] identified major obstacles and incentives for adaptation based upon representative focus groups, Kuhl et al. [40] examined in more detail some of the challenges and implementation barriers of evacuation in an environmental justice community, and Kirshen et al. [41] addressed how to involve vulnerable exposed populations in urban adaptation strategy planning and the use of multi-stakeholder collaborative processes.

\subsection{Data Collection}

In this study, we used several methods to gather site-specific data. We executed site visits, landscape analysis [15], historical analysis, and interviews with developers, researchers, public officials, and users of public space [42]. The site-specific data on hydrology, climatology, and geology were collected through observation of the area and the study of local databases. Semistructured interviews (Appendix A) were conducted to validate this data and to gather information about problems and opportunities in vulnerable areas of East Boston. These interviews were held in March and April 2017. The selection of interviewees was done through snowballing and random selection during a community meeting.

\subsection{Landscape Analysis}

In the analysis of our data we applied a landscape analysis approach [15,16]. Landscape analysis is a broad notion for research that supports design processes and the coming into being of a design product such as a landscape plan [34]. As stated earlier, we focused on East Boston, a peninsula located on the eastern edge of Boston (Figure 2), and on the area's history, local hydrology, landscape ecology, and environmental (dys)functions. 


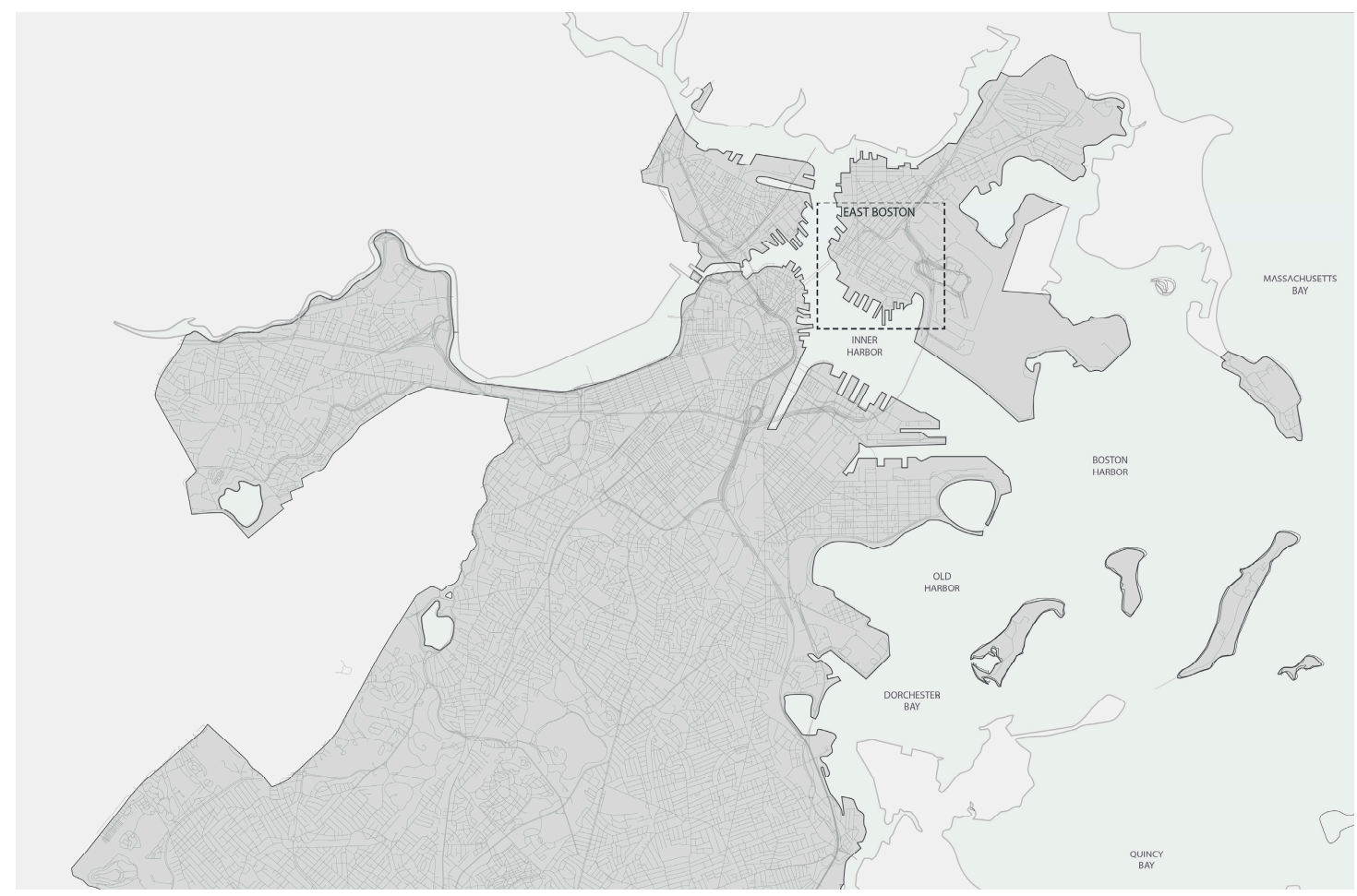

Figure 2. The location of the East Boston case study in the wider metropolitan area of Boston, USA. The delineated shaded area is the City of Boston. Source: Authors.

The historic analysis of the area was conducted by desk research of public information and geographic data such as historic maps of the area. This enabled us to study the general evolution of the area between 1630 and 2018. The local hydrology and ecology were studied through a GIS analysis of the area's elevation; drainage and ecological structures such as the roads, marshes, beaches, and parks in the area; and projections of the 100-year-flood mark for coastal flooding. Main data were retrieved from the open database of the city of Boston. The analysis was conducted in QGIS.

Functions and dysfunctions were analyzed in QGIS and based on both open data and observations in the area. Photographs were outlined against the area's map, and then key spatial problems for sites, the general structure of the area, and the constraints due to the existing landscape and key features such as roads and buildings were identified based on expert judgement. Moreover, the accessibility of the area and the waterfront was analyzed. The city of Boston had modeled climate scenarios available [43], which we used for the analysis of climate impacts on the area regarding sea level rise.

\subsection{Research-Through-Designing}

In the second step of our analysis, we combined the information from the landscape analysis with pathways thinking concepts to critically design for the area based on research-through-designing (RTD). This research method actively employs designing to develop new knowledge [34]. RTD was used to create a landscape architectural design for flood-prone areas in East Boston in order to investigate the landscape implications of pathways thinking.

The case-based design enhanced our understanding of the spatial implications of different measures and showed if they were spatially feasible or not (adaptive or maladaptive, cf. [3]), and, if feasible, what measures might look like in a particular setting and what information this would offer policy-makers as to their adaptation tipping points and the logical connection of possible measures into pathways [20,44].

The RTD process was based on several elements underlying pathways thinking, such as identifying objectives, generating a set of options for measures, assessing options as to the uncertain driver of change, and identifying pros and cons of options based on multiple criteria [20]. 
Then, the resulting coarse pathways were assessed in four different steps: designing, assessing, refining, and testing [45] (Figure 3). Simple conceptual drawings were made to explore how the pathways might turn out spatially, and these were held against the pathways for the next step of refinement. We chose to focus on three archetypical design strategies which were suggested by Smet [11] to handle uncertainty and which are also available for landscape design in the context of pathways: multifunctional (robust), flexible, and supplementary (adaptive) design strategies. These strategies are high-level approaches to reducing risk and acknowledge and account for irreducible uncertainty. The strategies do so in different ways and can therefore constitute an adaptive approach. Each conceptual design offered feedback on the different trajectories on the coarse pathways map and the possibilities to later switch to other measures. After five iterations, these steps resulted in a satisfying outcome.

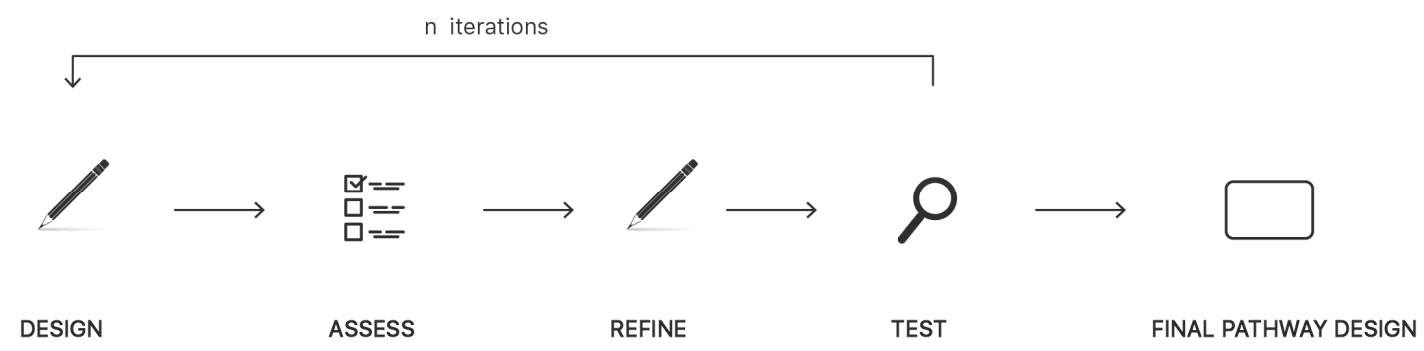

Figure 3. The research-through-designing process used: reiterating four consecutive steps. Source: Authors.

After conceptually designing the pathways, the entire sequence of spatial adaptation measures was visualized through time and in full detail for East Boston. This provides details on which measures can be implemented, for which sea level rise they should be implemented, and what they would look like. Based on this, our final design step was to translate the pathways from a high-level proposal into a detailed design, with an in-depth explanation and visualization of options for measures and the follow-up stages for keeping sea level rise in the far future at bay. This indicates how the landscape might transform in consecutive stages. The visualization also helps us to imagine what the results of a chosen measure could be and the spatial lock-in each consecutive stage brings with it. In the following section we offer the reader our results.

\section{The Landscape of East Boston}

In this and the following sections, we outline the results of our study. We first describe the outcomes of the landscape analysis as a stepping stone for the research-through-designing study on pathways for a climate-resilient East Boston (Section 5).

\subsection{The History of East Boston}

East Boston was developed from a set of islands in 1630, when Boston was first colonized by European settlers, despite the presence of a native American tribe called the Massachusett, into a world-famous shipbuilding area during the 19th century. To establish shipyards, wharves, housing for employees, and other harbor improvements during the maritime boom, large tracts of land in Boston were reclaimed from the sea. Moreover, the boom attracted a large number of immigrants. Coming from Europe and Canada, they turned East Boston into a working-class neighborhood. When, starting at the end of the 19th century, the shipbuilding industry declined, Logan International Airport was established in the 20th Century, causing local industries to further decline in favor of airport-related development and demanding further infill of land. As East Boston expanded by reclaiming land from the sea since its establishment, many parts are built on filled tidelands. Filled tidelands are relatively low-lying and, when located near the coastline, very prone to flooding.

Today, East Boston, as part of the city of Boston, is approximately $12.2 \mathrm{~km}^{2}$ and is a mostly residential area. Due to Boston's international airport, East Boston functions as the city's main 
transport hub. Therefore, accessibility to and from the neighborhood is pivotal to its functioning. East Boston can be accessed through the Callahan, Sumner, and Ted Williams Tunnels, a metro line, ferries, and roads from the north.

Currently, the neighborhood houses a community of over 40000 inhabitants, many of which can be characterized as low-income and socially vulnerable. East Boston is a culturally diverse area, with people of many different races and backgrounds. Its geography, since it is surrounded mainly by water, gives the neighborhood a strong identity, while at the same time a sense of isolation. Over time, residents, builders, and regulators have developed a love-hate relationship with the shoreline, which has led to inaccessible and unattractive waterfronts in some parts of the neighborhood.

\subsection{Climate Change Projections}

East Boston is prone to both coastal and pluvial floods. Coastal floods in Boston are caused by high tides and storm surges that cause temporal extreme sea levels. Sea level rise has already caused certain low-lying areas to flood during regularly occurring high tides, called astronomical high tides (locally known as wicked high tides). Storm surges in the case of Boston are particularly dangerous when north-eastern winds (Nor'easters) or extratropical storms occur, directly exposing the city to surging water from the Atlantic [46]. Hurricanes are less dangerous due to the protection of Cape Cod, which prevents hurricanes traveling from the south to directly hit the city [47]. When large amounts of rainwater fall and cannot be stored or drained, pluvial floods might occur. For East Boston, the factor of greatest concern is the occurrence of a combination of these two types of floods [46]. F The entire range of sea level rise projections is a rise of $12 \mathrm{~cm}$ ( $0.4 \mathrm{feet}$ ) in 2100 under an extremely low scenario (RCP (representative concentration pathway) 2.6) to a $2.9 \mathrm{~m}$ (9.5 feet) rise in an extreme upper level (RCP 8.5) situation (compared to 2000). We chose to focus on expectations based on an uncertainty range between $23 \mathrm{~cm}$ and $91 \mathrm{~cm}$ sea level increase by 2070 (compared to 2000). The caveat of this choice is that sensitivity of the measures beyond this range is not included, so before deciding on a first measure, this should be taken into account. Stress testing different measures and follow-up options is particularly important for preventing long-term lock-in or lock-out, rendering the choice unsustainable. We used these sea level rise projections to create inundation maps to analyze which areas will be exposed to coastal flooding (Figure 4). We did so for the effects of these scenarios for the average monthly high tide, a $10 \%$ annual chance storm, and a $1 \%$ annual chance storm. The $1 \%$ annual chance storm is a storm event leading to flooding that has a $1 \%$ probability of being equaled or exceeded occurring in any given year; it is also referred to as the "100-year flood" [48]. It indicates the annual exceedance probability (AEP) and is broadly used for coastal planning in the United States.

A key element for the risk on coastal flooding are flood paths (Figure 4). Through flood paths, water can flow over land and inundate larger, low-lying areas inland. The implementation of flood protection systems targeted at blocking these flood paths can adequately address coastal flooding problems for East Boston. Our analysis shows that around an increase of $23 \mathrm{~cm}$ (Figure 4a), four critical low-lying entry points along the coast allow for inland flooding [43]. At the southern end of East Boston, three flood paths exist, all causing flooding of the East Boston Greenway-a shared-use path and park that connects several open spaces. A large part of this Greenway runs between the airport and a residential area. The Greenway cuts deep into the urban fabric and lies roughly $60 \mathrm{~cm}(2 \mathrm{ft})$ below the current high tide level. The fourth flood path is located on the west side of the area, exposing the area south of Bennington Street and exposing the Sumner and the Callahan Tunnel entrances to floods. Because of these entry points, $16 \%$ of the land area in East Boston may be exposed to low-probability flooding in the near term, which steadily increases to almost $50 \%$ with a sea level rise (SLR) of over $90 \mathrm{~cm}$ [43]. Currently, the Lewis Street waterfront already experiences occasional flooding, such as on March 2, 2018, when a Nor'easter hit Boston's coast. Flooding through these paths is thus already a prevalent threat to some parts of East Boston.

We also analyzed which residential parcels will be located within the 100-year floodplain. Of the current residents numbering over 40,000 in East Boston, near future high tides might expose around 
300 people to flooding (frequent flooding), and a 100-year flood could expose up to 7020 people to flooding [43]. With an SLR over $90 \mathrm{~cm}$, these numbers increase to around 6200 people (flooding from high tide) and 19,070 people (flooding from a 100-year flood). Not only half of the East Boston area, but also half of its population will be exposed to flooding in the future [43].

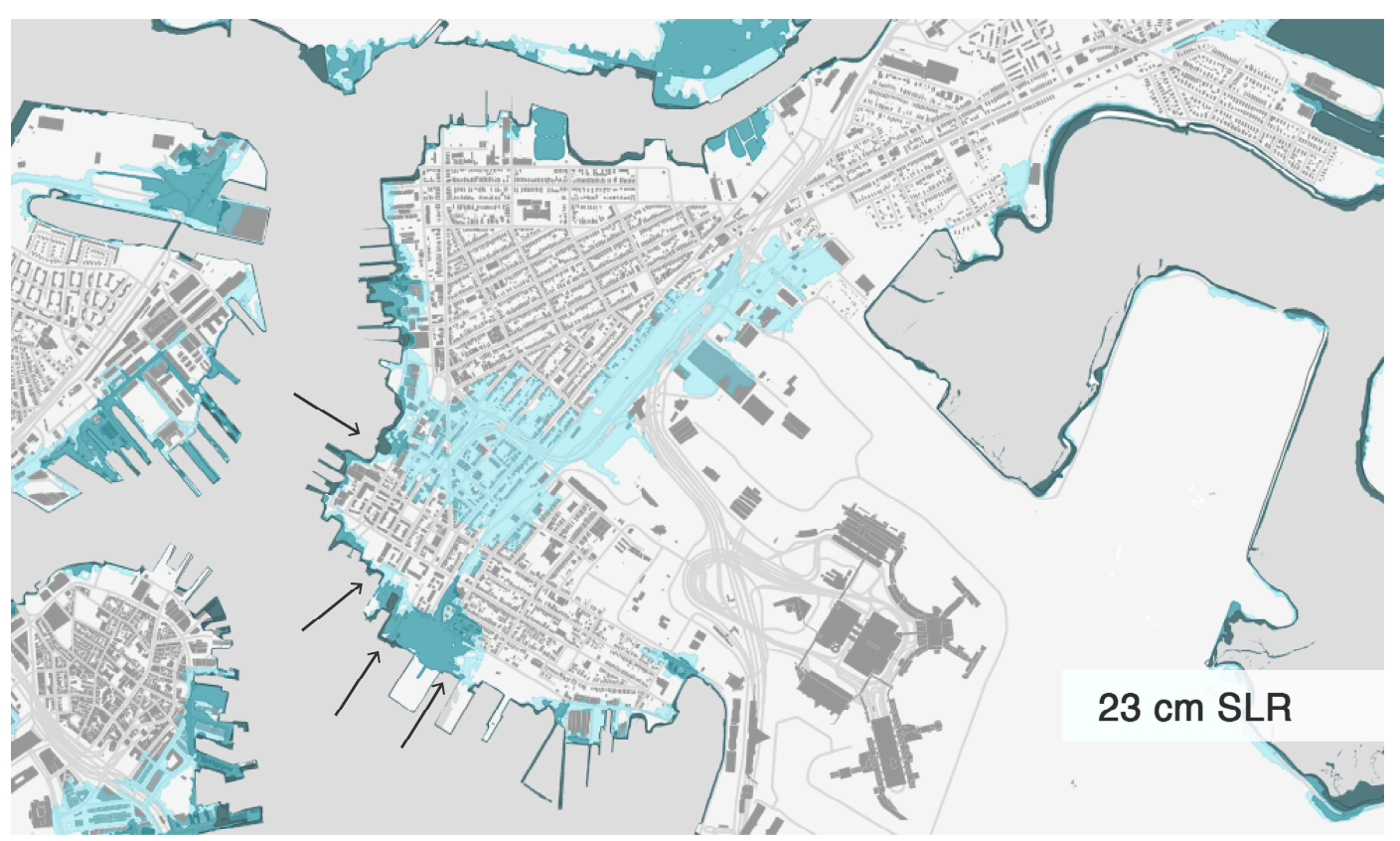

(a)

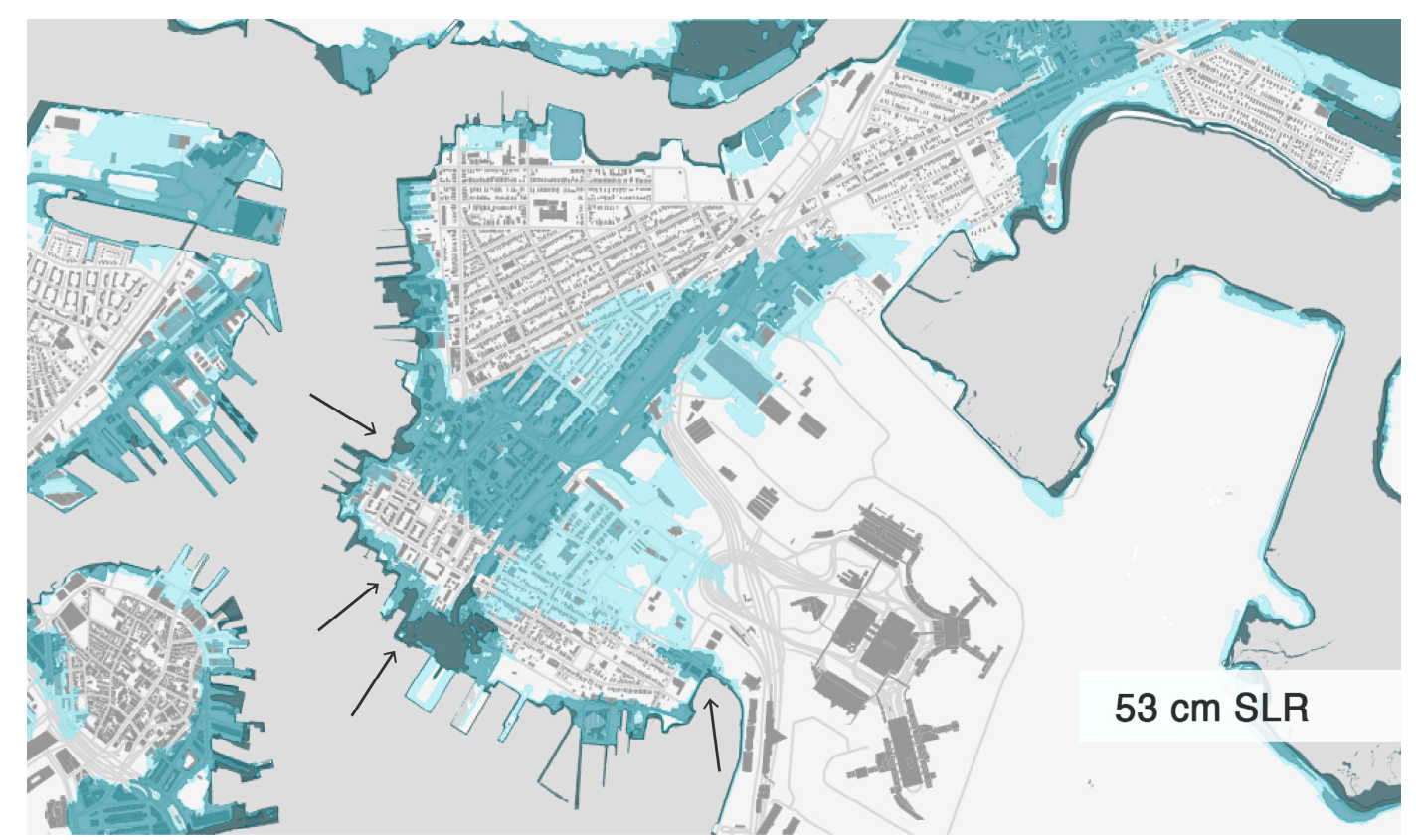

(b) 


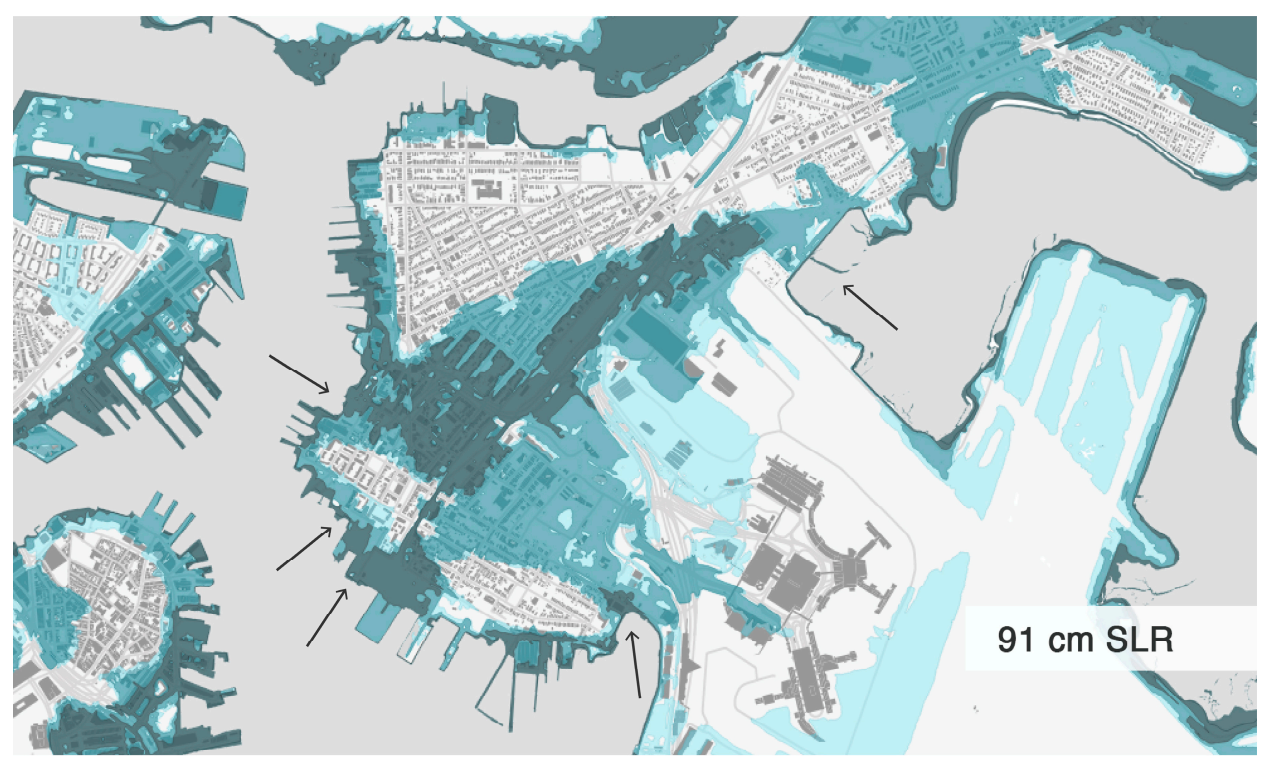

(c)

\section{LEGEND}

flood projection at high tide

flood projection $10 \%$ annual chance storm

flood projection $1 \%$ annual chance storm

(d)

Figure 4. (a) Inundation with a $23 \mathrm{~cm}$ sea level rise including inundation entry points (arrows); (b) inundation with a $53 \mathrm{~cm}$ sea level rise; (c) inundation with a $91 \mathrm{~cm}$ sea level rise; (d) legend indicating flooding when current a high tide, a 10\% or $1 \%$ annual storms occurs. (Adapted from [43]). Source: Authors. 


\subsection{Spatial Problems and Opportunities}

To make a landscape design of pathways feasible, we need to address existing spatial problems and capitalize on opportunities. We identified four problems for East Boston that have a spatial connotation. First, there are several spatial barriers disconnecting communities, particularly for Maverick Square, Eagle Hill, and Jeffreys Point. These spatial barriers include highways, subway tracks, the Greenway, and dead-end streets that cut off walking paths and impose additional walking distances. A second spatial problem we identified is the unattractiveness of waterfronts. Since East Boston's maritime heyday is over, this once vital part of the area has been neglected. Currently, the waterfront lacks vitality and attractiveness. The third problem is the inaccessibility of parts of the waterfront, separating neighborhoods from the water. Waterfronts are often obstructed by walls, fences, or buildings which form both physical and visual barriers that make many sections of the waterfront inaccessible or invisible. A fourth and last spatial problem we identified is dense urbanization with a lack of permeable areas and green, open space. The resulting lack of infiltration capacity might prolong or worsen pluvial flooding and prohibits large-scale adaptation measures.

Besides these spatial problems, we identified two spatial opportunities to enhance climate resilience in East Boston. A first and major opportunity is to enhance water storage in the area by (re)greening and increasing the total amount of permeable surface to catch, store, and infiltrate precipitation and overtopping sea water. Based on site analysis and mapping, we found that, in addition to smaller areas which might be turned into green area, the East Boston Greenway provides a major opportunity to store and drain water because of its location, shape, and position in the landscape. The Greenway is one of the lowest parts of East Boston, which causes water to naturally flow to it. Making sure precipitation and overtopping coastal water is contained within this area could immediately reduce flood risk in the area. Creating more accessibility by connecting the Greenway with residential areas and streets could provide additional benefits for the community, such as possibilities for a variety of recreational activities and experiences (e.g., walking, bicycling, fishing, and enjoying the view of the sea).

Second, we see the opportunity to include climate change adaptation with the needed investments in the area for urban renewal. In the past decades, the buildings and public spaces have deteriorated, and substantial investments in the urban renewal of several parts of the area are now required. Investments in urban renewal offer an opportunity to achieve climate resilience goals while spatially uplifting the area. In particular, East Boston has a lot of undeveloped parcels along the waterfront, and some of these former industrial sites are currently being transformed and turned into housing and public space.

\section{Pathways Design}

Based on the landscape analysis, we created pathways in order to assess them through a research-through-designing approach. To do so we took two additional steps: defining additional design objectives needed for an integrated spatial design and defining appropriate measures to feed into the pathways.

\subsection{Design Objectives and Measures}

The main objective of the measures in the pathways was to create a spatially adaptive design which offers both pluvial and coastal flood prevention. The pathways offer options on measures with a protection level based on a frequency of a 1:100 coastal flood event ( $1 \%$ annual chance flood). The actual timing of sea level rise and related actions are uncertain. Under the conditions that these objectives are no longer met, "tipping points" are reached in the ongoing trajectory of change. Such a tipping point marks a dead end for a specific path and a need to take additional measures to protect the area against flooding. 
To create pathways, different measures need to be distinguished and assessed as to their tipping points in face of SLR. The measures need to be beneficial in light of the stated objectives and have relevance for the situation in East Boston. We identified 14 flood-reducing measures divided into hard protection, soft protection, and accommodating measures [49] and assessed them through a multicriteria analysis. Note that our analysis was applied only for the relatively near future (e.g., 50-150 years depending on the uncertain rate of SLR). We did not assess the applicability of these measures for SLR extending beyond the mentioned scenario above, thus limiting the temporal extent of these measures to protecting up to a 1:100 year chance of flooding.

Flood protection measures are designed to keep the water out of the area as much as possible by a coastal defense system. We distinguish "hard" protective measures which are infrastructure-based and "soft" measures which are nature- or ecosystem-based. Such measures can be used simultaneously in a spatial design and even in one location, such as creating a dune system over a seawall. Hard measures we assessed for East Boston include seawalls, terraced seawalls, deployable floodwalls, dikes, elevation, and large coastal barriers. Soft measures we considered are ecosystem-based approaches reinforcing natural defenses such as dunes or beaches, floodable parks, revetments, and living shorelines based on replacing man-made obstacles with wetlands and indigenous plant species [50].

Besides using flood protection measures to keep water out, accommodating measures allow for safe, temporary inundation. This can be done by flood-proofing buildings in the area, guiding the flow of water across the landscape, storing large volumes of water on land, and speedy removal of excess water from inundated areas by using pumps, infiltration, and alternative drainage routes. A particular accommodating measure on a neighborhood scale is to retreat from the coast (retreating in general out of the 1:100 year floodplain is a different strategy altogether, removing the risk of flooding entirely). Retreating includes withdrawal, relocation, or abandonment of built assets that are at risk of coastal flooding, which were all considered as one measure. These measures allow human activities and the hazard to coexist. Accommodating measures such as elevation of buildings are often intended to complement traditional flood-preventive measures such as floodwalls.

Our multicriteria analysis in this study was set out to assess the measures on four aspects in addition to their spatial fit, which was assessed during the research-through-designing process. We assessed the measures as to their physical impact, visual impact, regulatory impact, and relative costs (Figure 5). We did so on a three-point Likert scale (low, medium, high). Physical impact is based on the relative footprint of measures (e.g., a dike has a larger footprint compared to a deployable flood wall). Visual impact was assessed based on the height and location of measures and the relative ease with which designers can aesthetically fit them into the local landscape (based on expert judgement). Regulatory impact was assessed mainly for industry and was based on water depth as an indicator for accessibility for marine industries and necessity to leave the shore undeveloped for a specific flood preventive measure (e.g., a dune system demands more coastline and less development compared to a floodwall which allows for marine industries). Costs were based on an indication for the relative implementation and maintenance of each of the measures to give a notion of the relative investment compared among the different measures. Combined, the scores for these four variables led to a score $(+,++,+++)$ for the applicability of the measure.

The multicriteria analysis led to ten applicable measures (scored ++ or +++ ) to be used as starting points in the research-through-designing endeavor. The measures were mapped against the scenarios identified above as to the probable tipping point when a measure would not suffice for the objectives. Although done in a coarse manner, this gave a first selection and structure for the different measures to abate the consequences of sea level rise. 


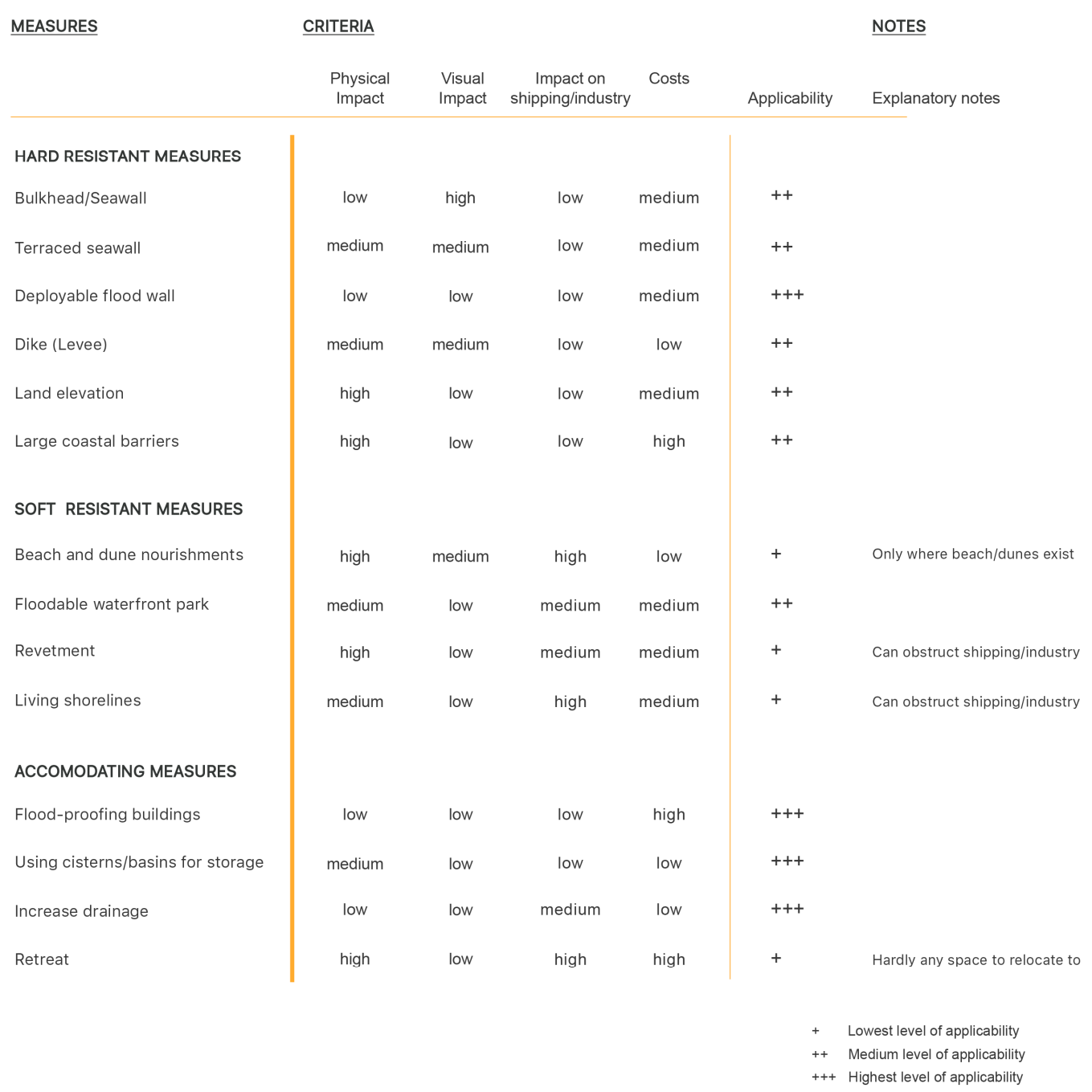

Figure 5. Results of coarse multicriteria analysis for 14 measures to increase the flood preparedness of East Boston. Source: Authors.

\subsection{Creating and Testing Pathways}

Based on the selected measures we started the iterations necessary in research-through-designing. The first spatial sketches gave clues as to the feasibility of different measures in the existing landscape and the possible transformation of the landscape over time. Based on this first iteration we created a pathways map with nine alternative measures specified for applicable height for East Boston (Figure 6). We used the extend of SLR to identify tipping points for measures. We adapted the pathways method by indicating tipping points not in time, but based on SLR, making the map independent of the rate of climate change and the uncertainty about the rate of change translated into the $x$ axis. Based on this map we started a new iteration to identify an adaptive design based on the area's specific configuration with specific attention to the entrances of the flood pathways into the area.

We went to five iterations based on this pathways map. In each iteration we created and tested designs according to the city and community objectives and three sorts of design strategies: flexible, multifunctional, and supplementary strategy (see Section 2.3). While doing so, we tested the pathways as to their spatial consequences and fit in the landscape. Thus, each design choice led to a path (identified based on an archetypal strategy) that went in a crisscross manner through the map due to the complementarity of different measures when trying to explicate the pathways for a local landscape such as that of East Boston (Figure 7). 


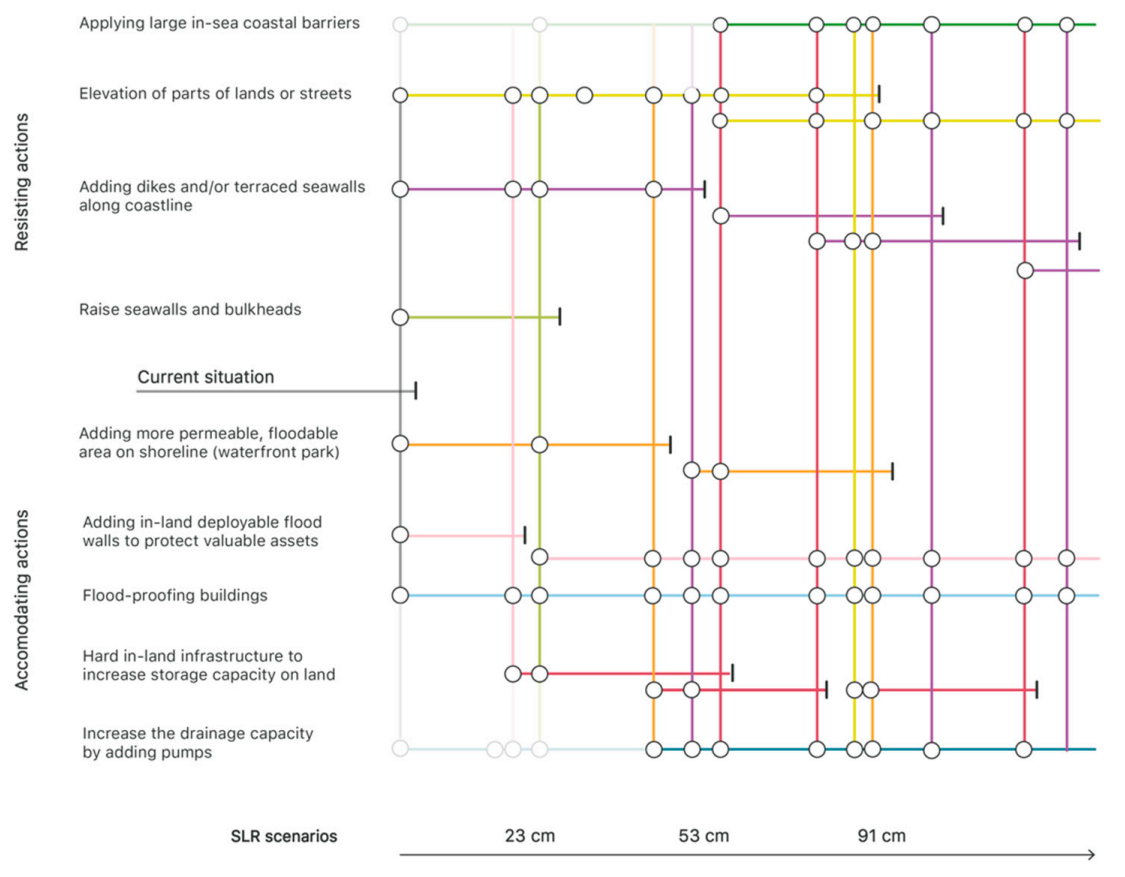

Transfer station to new action | Adaptation Tipping Point of an action (Terminal) _ Adaptation Pathways

Figure 6. All applicable measures mapped according to the adaptation pathways method (Adapted after [20]). Source: Authors.

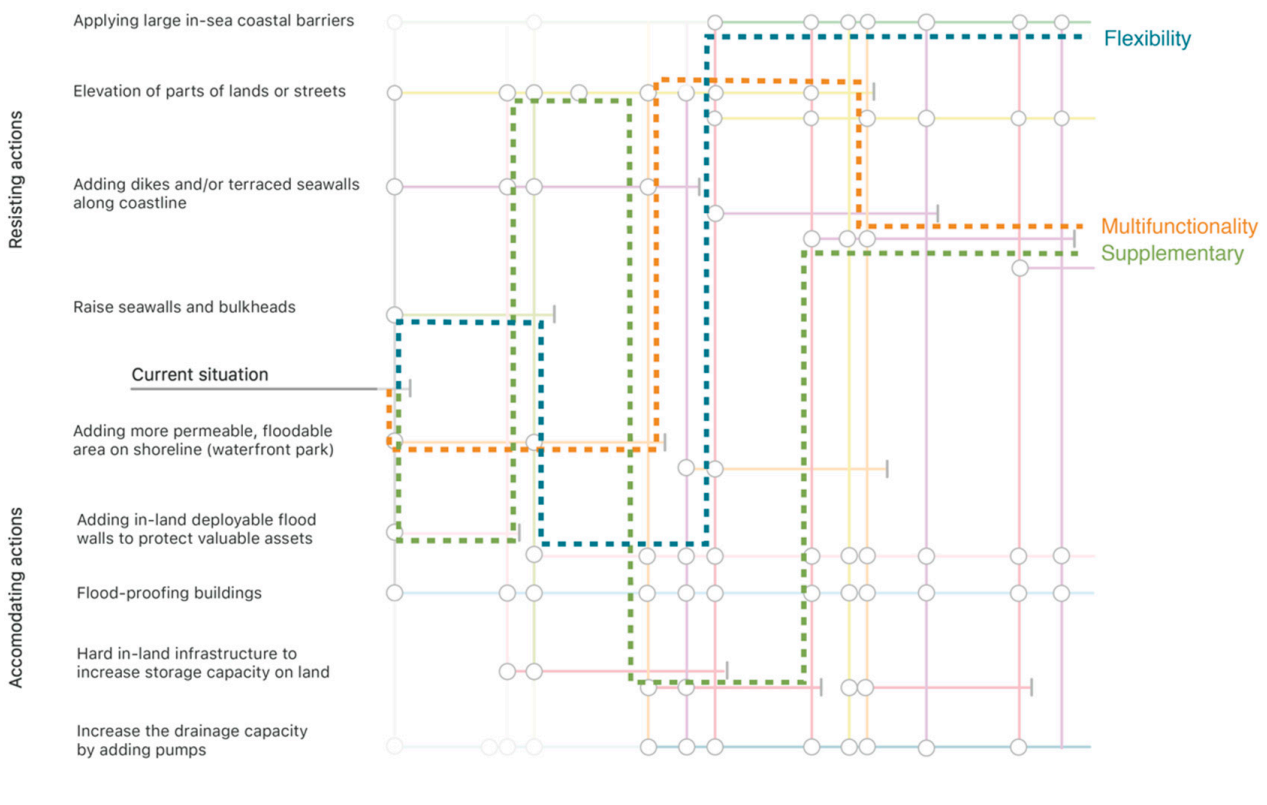

SLR scenarios

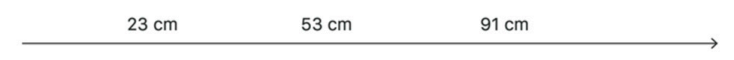

Transfer station to new action

| Adaptation Tipping Point of an action (Terminal)

- Adaptation Pathways

Figure 7. Tracing spatially explicit trajectories of change, based on the three design strategies used to create an adaptive landscape design, leads to paths crisscrossing through the map. Source: Authors.

Each of the three design strategies was assessed regarding geographic fit, contribution to reducing flood risk, local spatial quality, and community preferences, and placed in the total sequence of the pathways map. In our design we queried each of the possible measures as to the lock-out they create 
for future measures or possibilities for supplementing each other (Figure 8). This conceptual step helped us to see how measures can be added to each other over time and work together as a larger system that keeps growing along with changes in the environment and society. Pathways thus focus on creating multiple interventions that allow for a gradual development of the area instead of abrupt large-scale interventions. Taking smaller steps and decisions allows the design to be adapted in the future when new knowledge becomes available. By creating diversity in the measures that are taken, the design also avoids the idea of putting "all the eggs in one basket", because if one part fails, the other solutions will still work. From such insights, there are several other measures and pathways that can be taken without losing on earlier investments.

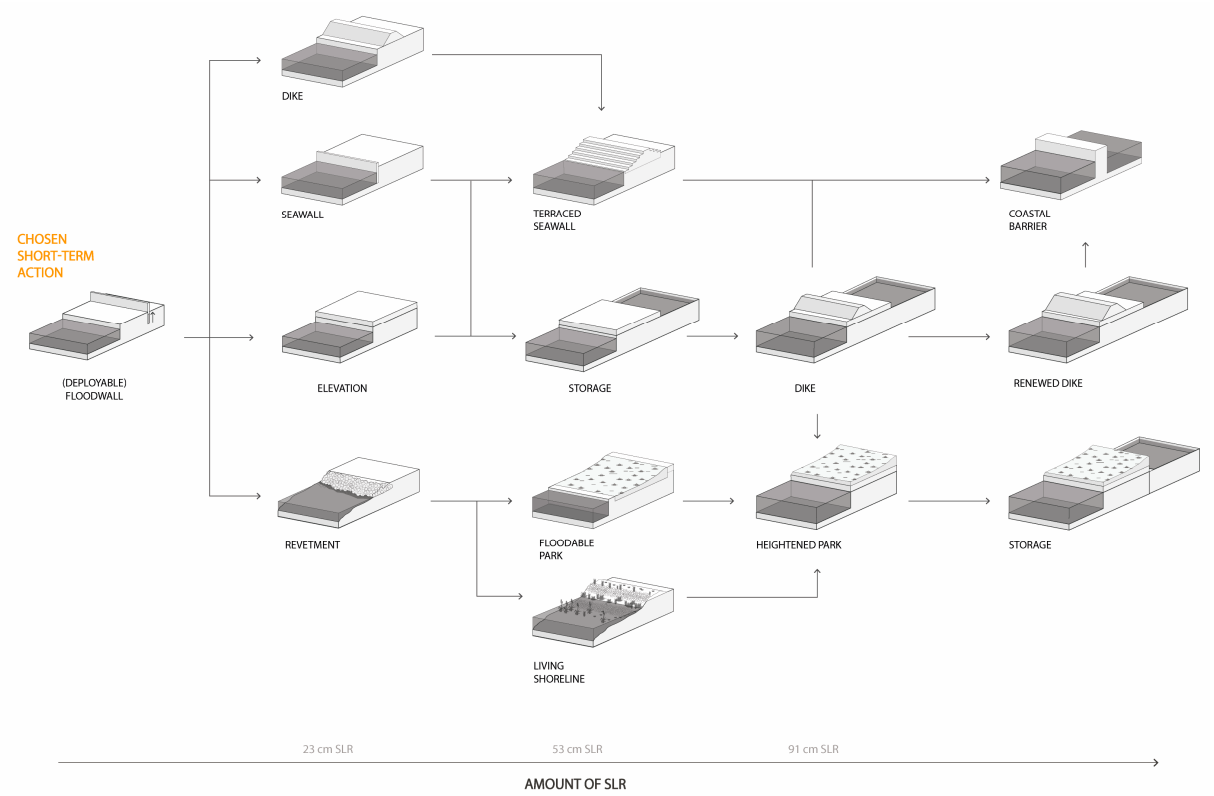

(a)

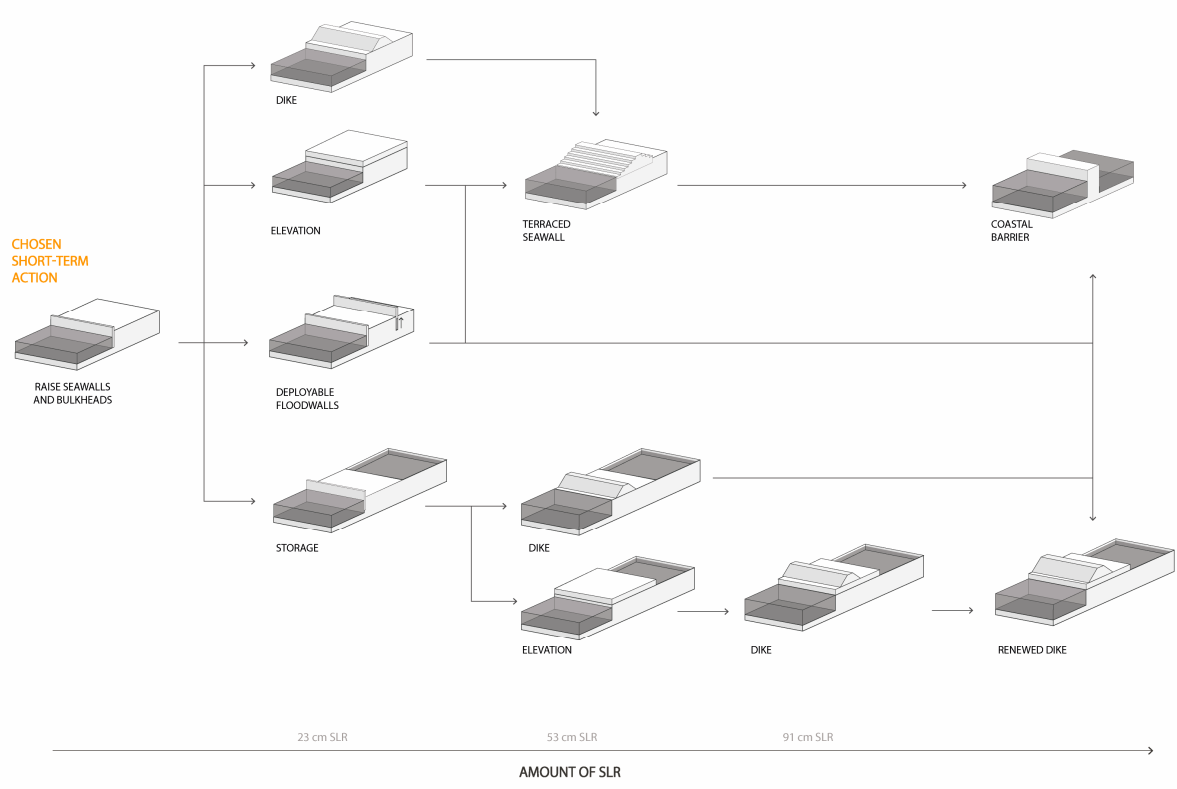

(b)

Figure 8. Cont. 


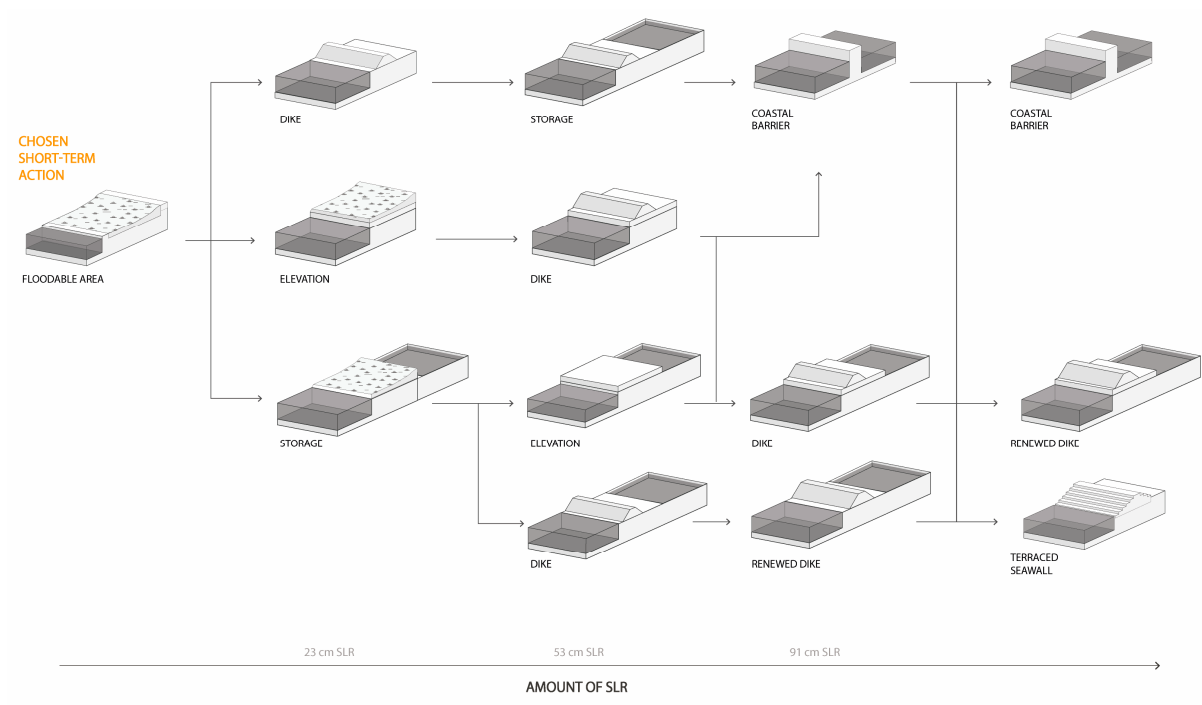

(c)

Figure 8. (a) Symbolic depiction of the pathway map and possible diversions between measures without preempting on past investments for the supplementary design strategy; (b) the flexible strategy; (c) the multifunctional strategy. Source: Authors.

\subsection{From Pathways Towards an Adaptive Design}

In the final step of the case study we built onto the previous steps by turning one set of sketches, those for the supplementary pathway, into an adaptive design that serves as a design of how the trajectory of the future development of East Boston might occur. This design was made to query the relevant effects of each measure and their transformation in time, not as a final solution: this can only be done after the future has occurred. In order to do this, we spatially visualized the supplementary adaptation pathway based on the entire sequence of spatial adaptation measures through time in this path and for the particular locations in East Boston (Figure 9). Short-term measures involve placing deployable floodwalls and elevating a few critical areas. For medium-level SLR, exposed areas can be protected by creating areas where overtopping can be stored on land. When the storage capacity limit is reached, on the higher level of SLR, the addition of dikes and terraced floodwalls can protect the area from even higher sea levels, while consideration can be given to other measures and pathways to reduce inundation risk. This translates the symbolic depiction of the pathways into details on which measures should and could be implemented, where they should be implemented, and how they spatially fit into the sequence of transformative change of East Boston. Besides the visualization of this adaptation pathway, the other possible measures from the pathways map are also visualized to help keep in mind which diversions remain as options after the implementation of different measures. In this conceptual visualization, adaptation measures are integrated with the development of open, public space. This resulted in a combination of actions located both on the shoreline and further inland, as can be expected from a supplementary design strategy.

The last step we needed to take was a transformative design for each of the locations where a measure needed to be fitted in with the consequences of its adaptation over time. We show this for one path to illustrate how a landscape design can support the fit of measures into a particular context. For each moment in time when a choice is made, such a design endeavor must be repeated for the different options at hand. After visualizing each step in the transformation indicated in the pathway, we also designed for the particular locations to explicate the insights from the sketches and to inform what a measure might look like in normal circumstances and when submerged. One of these designs is the entry point of a flood path on the south-west side of East Boston (adjacent to the existing Piers Park). 


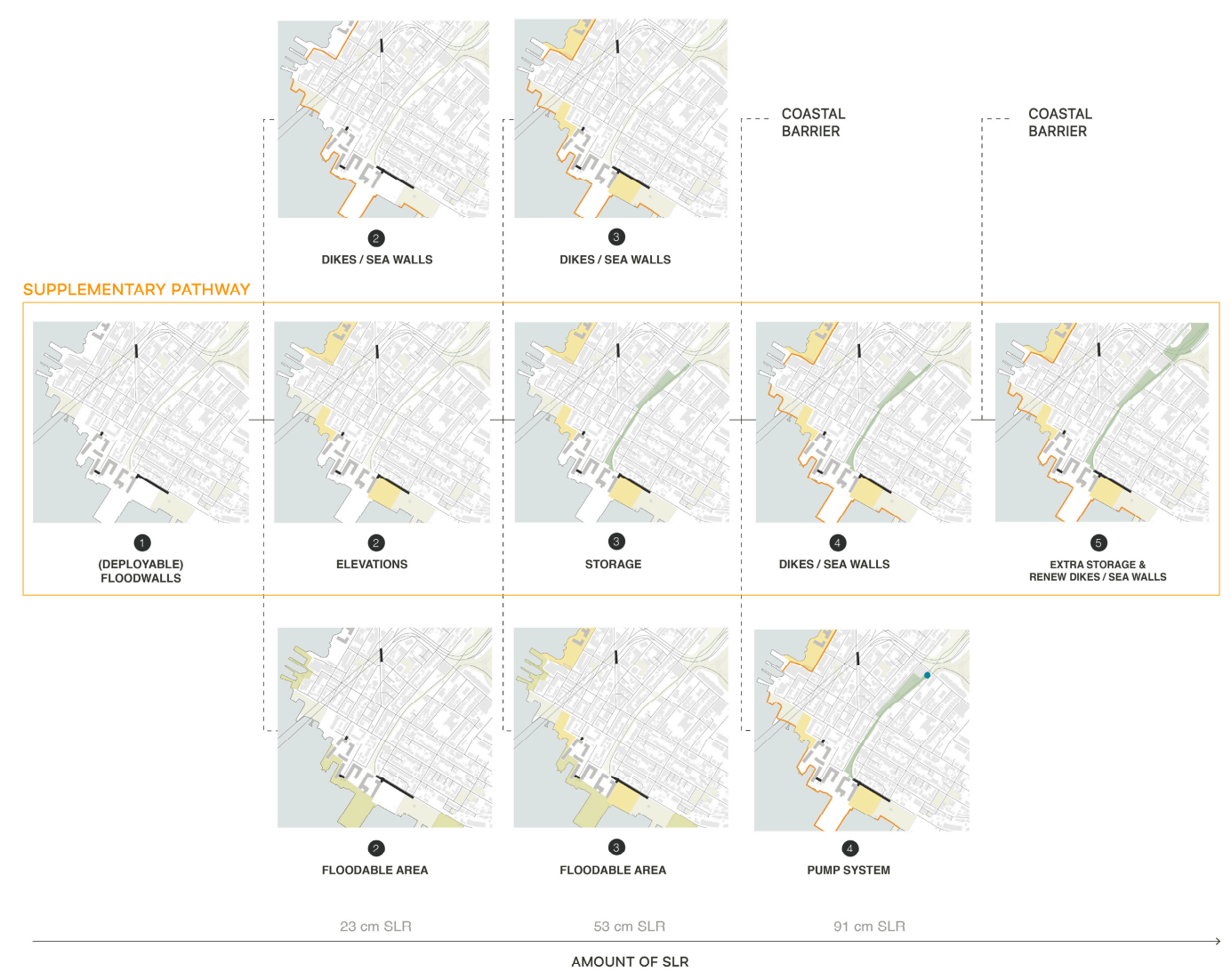

Figure 9. The phased implementation of the transformation of East Boston through a sequence of measures from the supplementary pathway. Source: Authors.

At this location, a park can be created which is robust to some salt water due to irregular coastal flooding. When flooded, a deployable floodwall prevents intrusion of flood water into the city (Figure 10a). The design also allows for later adaptations: we depicted the heightening of the central part of the park (Figure 10b), but a dike or a floodwall are other measures still available. If sea levels rise even further, an option is to store flood water in the Boston Greenway (in which the low floodwall retains its function but with some minor adjustments) (Figure 10c). This option is explicitly left open in the park design so no valuable trees or other investments are preempted in a later stage, while the options allow for gradual transformation of the Boston Greenway into a suitable area for flood water storage. When sea level rise further increases and overtopping water becomes too much to store, an option still open to the city is the allocation of a dike along the waterfront (Figure 10d), while retaining the attractiveness of the area and accessibility of the waterfront in the long term (Figure 10e,f). In this phase, other possible measures are to build a coastal barrier outside the harbor or to invest in pumping capacity to pump overtopping water back at once, delaying the choice for a dike or barrier. 


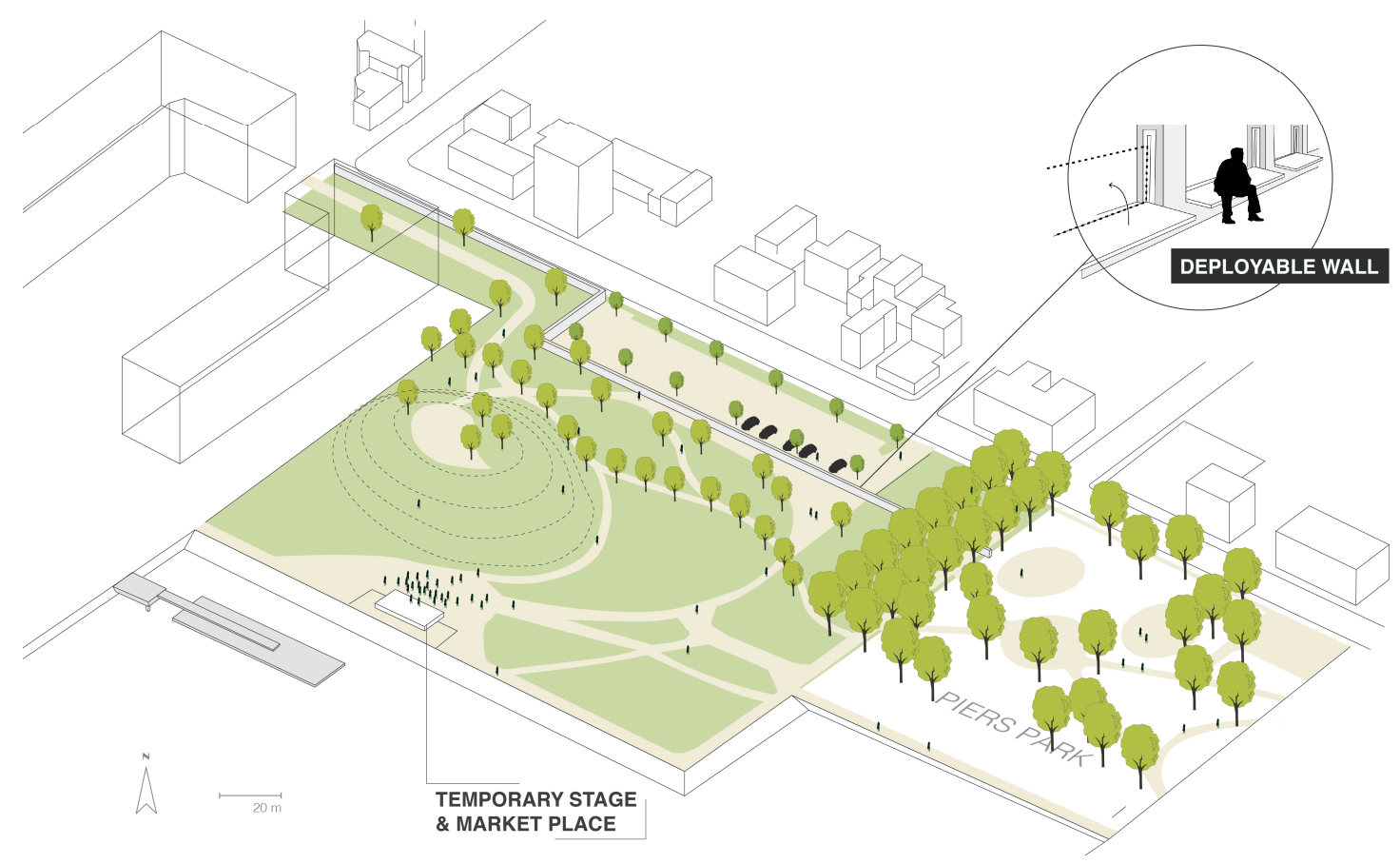

(a)

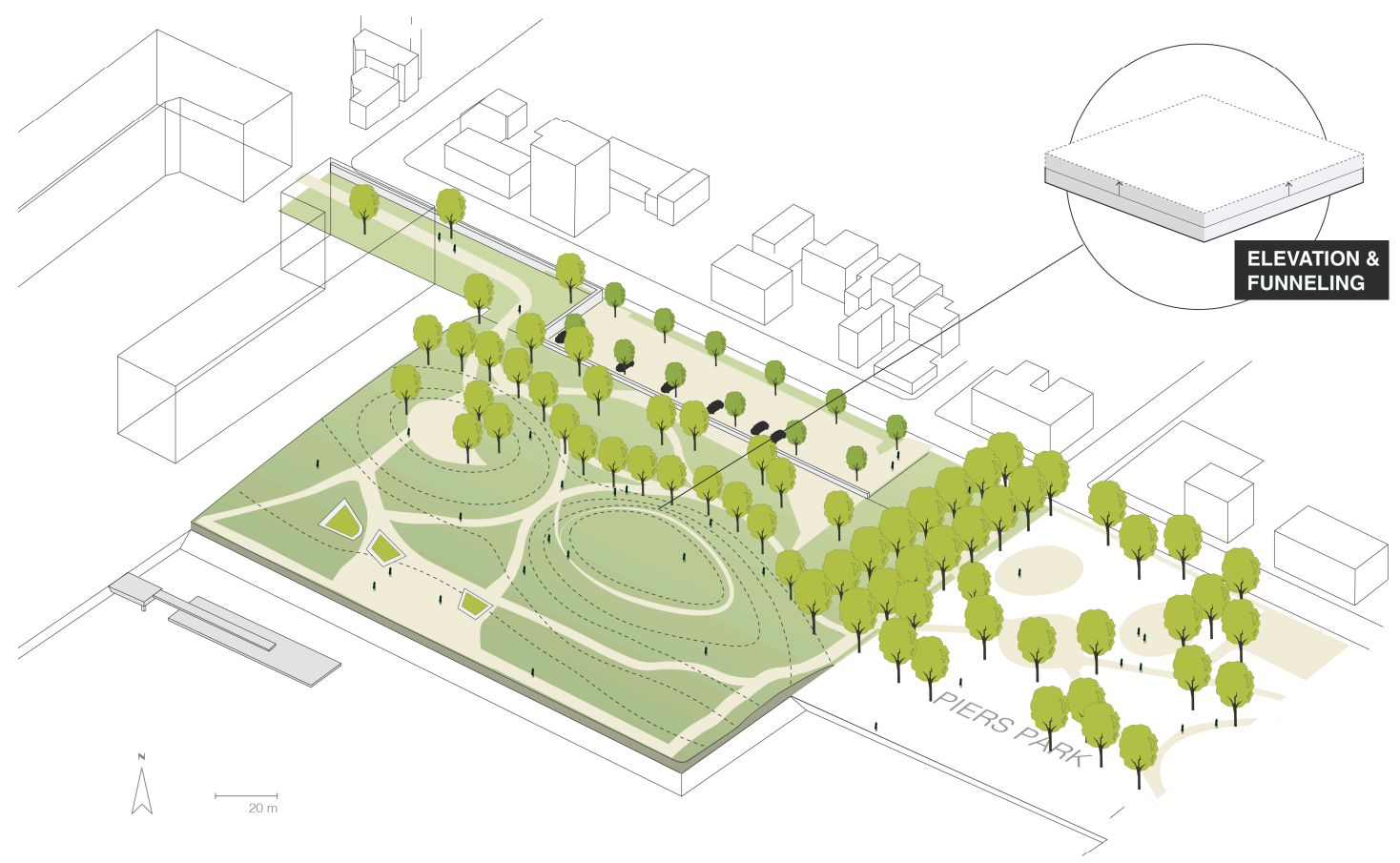

(b)

Figure 10. Cont. 


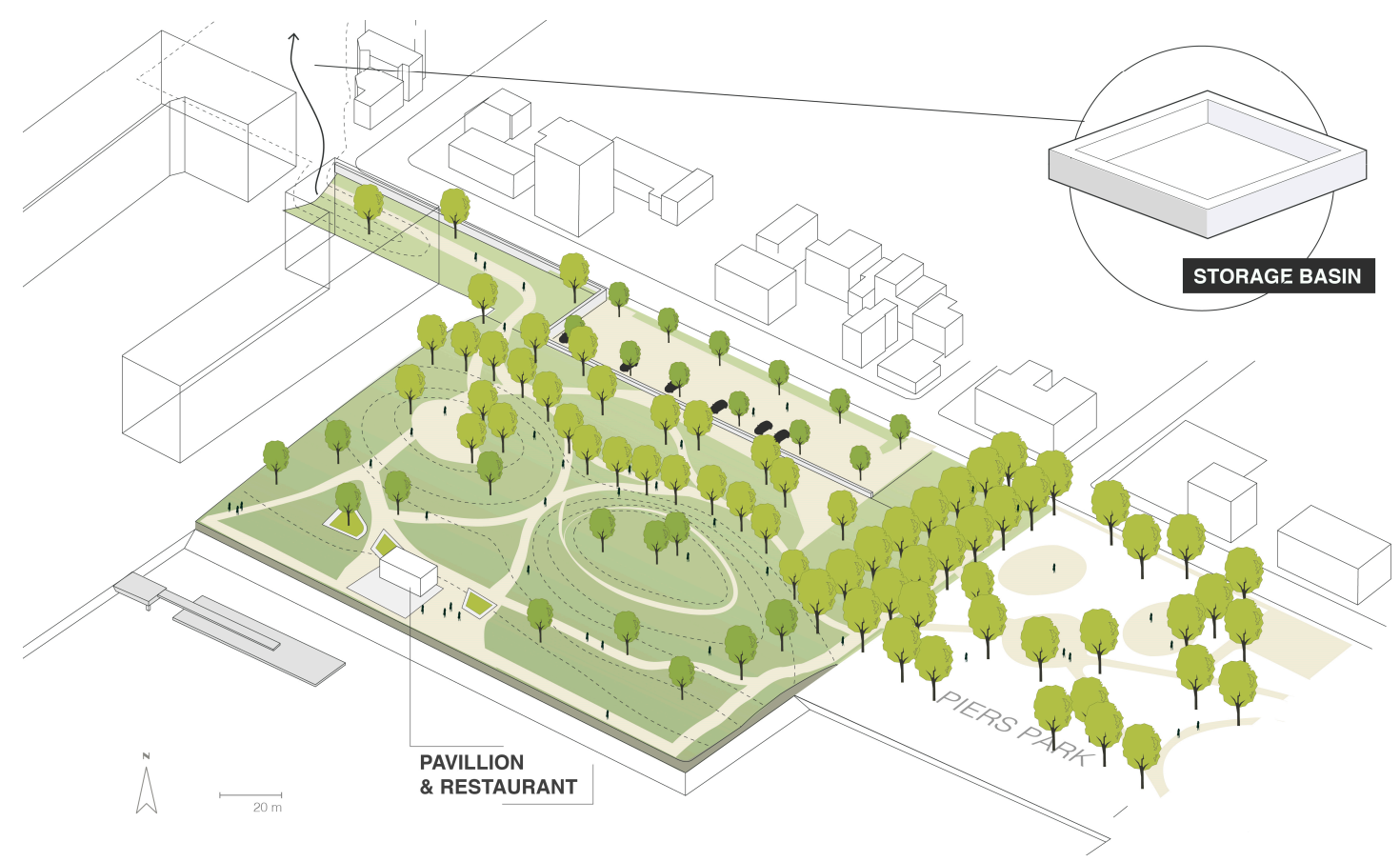

(c)

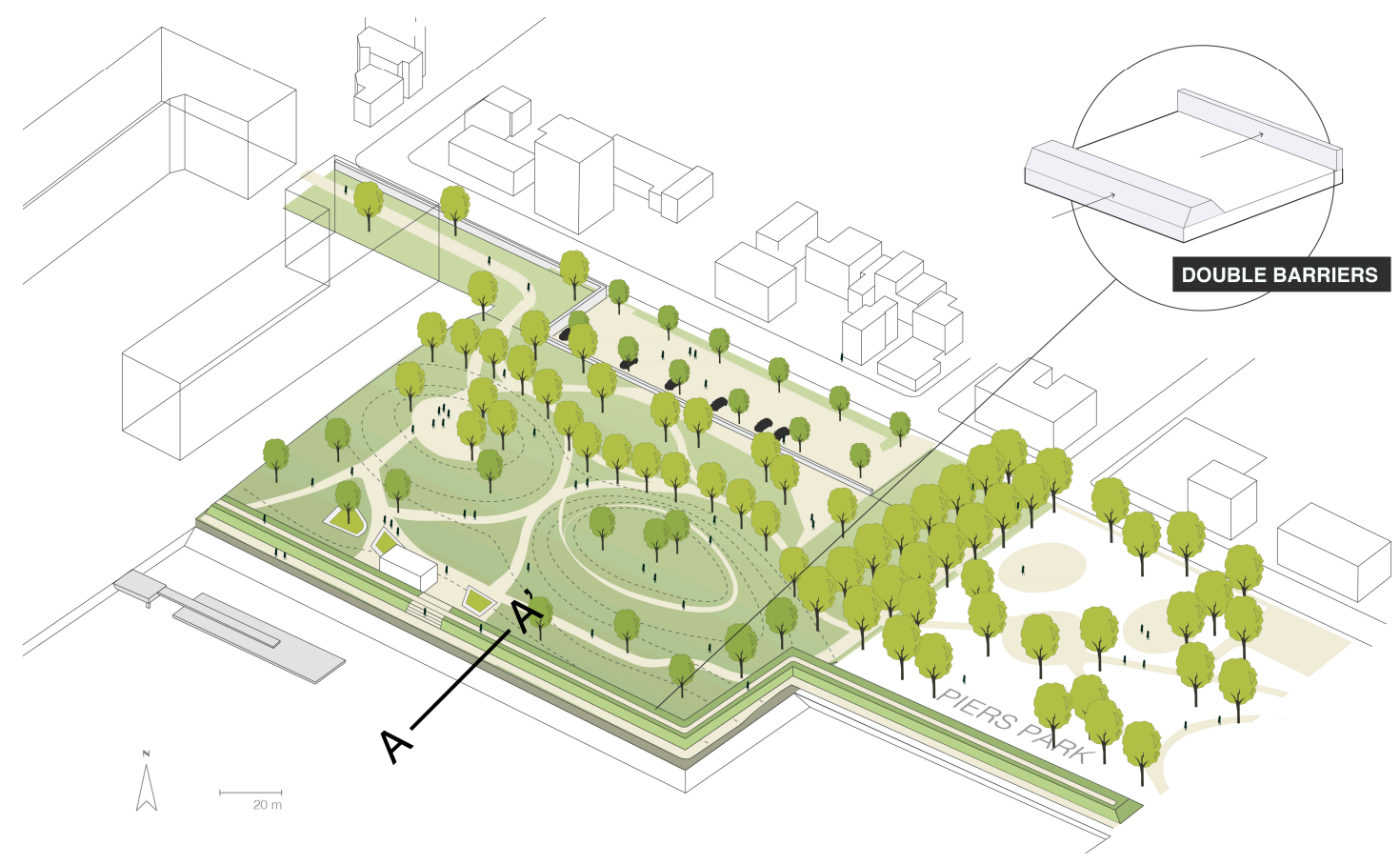

(d)

Figure 10. Cont. 


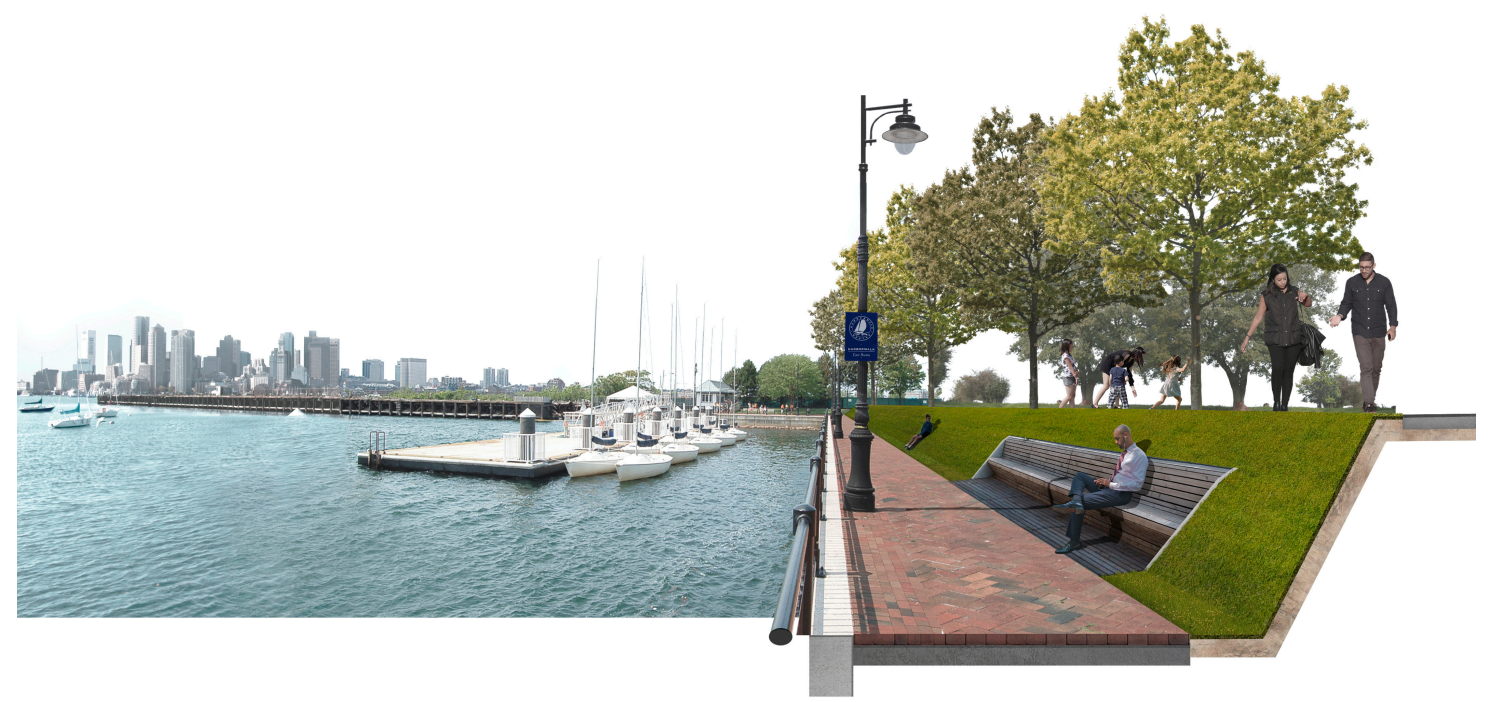

(e)

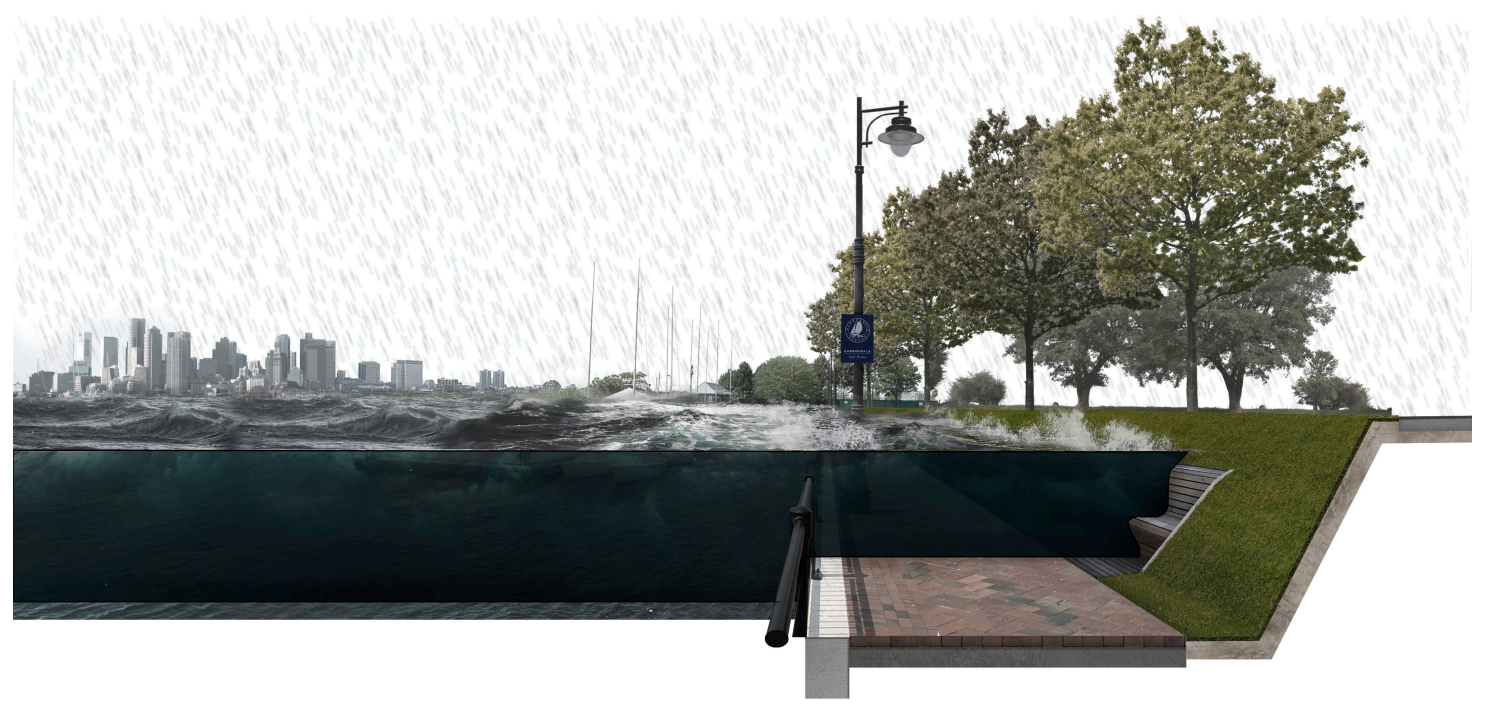

(f)

Figure 10. Designed adaptations of the waterfront park over time (adjacent to the existing Piers Park): (a) deployable wall; (b) heightening; (c) retention of overtopping water; (d) dike; (e) visualizations of the edge of the waterfront when not flooded and (f) when inundated (refers to section $A-A^{\prime}$ in (d)). This is one possible development path and gives an idea of how an area might transform over time. Source: Authors.

\section{Discussion: Landscape Implications of Pathways}

We started this study to find out what contribution pathways thinking offers to spatial design endeavors to make landscapes more adaptive and sustainable. Moreover, we also investigated what spatial implications are embedded in pathways thinking. Our results draw attention to the fact that most policy actions used in pathways thinking have spatial implications, while these implications are often understudied. The results show that the spatial implications of pathways can be made explicit through landscape design. Landscape design can be made more cognizant of future uncertainties by taking an adaptive and tipping-point-based design approach. Our contribution thus offers better understanding of the landscape effects of pathways for transformative change. Our landscape-based approach helps policy-makers to better understand the implications of pathways for existing and future landscapes. 
By using research-through-designing, we showed that design-based research methods offer opportunities to more deeply explore the effects of currently unknown future change on landscapes, such as effects caused directly by uncertain changes such as sea level rise and changed precipitation patterns, but also the lock-in and lock-out effects for future trajectories of change due to deliberate human interventions. To overcome some of the challenges of planning under uncertainty and to ameliorate policy-making processes, it is important to translate policy actions into spatial interventions and to investigate and forecast what their effect would be and which measures would be applicable and effective. By translating policy actions into landscape design, useful combinations of actions can be studied, visualized, and queried as to their consequences. By explicating the spatial implications of pathways of transformative change through research-through-designing, this study adds a spatial component to pathways thinking.

Our study also demonstrated how pathways thinking can be used to inform landscape architecture. To achieve sustainable and adaptive landscapes through design, pathways help landscape architects to be transparent about choices on flexible, supplementary, or multifunctional design strategies and help them avoid undesirable lock-ins or lock-outs through keeping options for other measures open. Designing for East Boston focused on capitalizing on the ongoing development and improvement of the area to achieve appropriate flood risk reduction while maintaining its functionality for the local community and leaving multiple options open for future choices.

Adaptive landscape designs are important for hedging against the negative consequences of long-term commitments often paired to the realization of landscape design. As the grid structure of East Boston shows, an established configuration of the landscape can determine the future of an area for many decades. Cities and their communities have to live with the consequences of the choices made in the design process [17]. For this reason, it is useful to be able to develop an adaptive design approach. These enable coping with the inherent impossibility of long-term accurate forecasts and prevalent ontic uncertainty about change (e.g., [1]). Moreover, the geographical characteristics of the area where measures are to be implemented determine their feasibility and the (mal)adaptive space available for policy-makers. A keen understanding of the landscape is essential for creating feasible pathways and to catalyze upon insights from pathways studies in general.

In addition, our results show the relation between policy options, spatial measures, pathways as trajectories of change, and the current organization of landscapes and point out that they mutually restrict or open up opportunities for directing adaptive interventions by policy-makers. In accordance with the study by Murphy et al. [7], the executed landscape analysis using pathways thinking for landscape design again shows the need to combine policy decision support tools such as adaptation pathways with site-specific research and local, place-based and tacit information, including community objectives and social dynamics.

Recent studies have shown the importance of including lived values in pathways thinking [8], the need to be cognizant of the effects of vested interests, different place-based value perspectives, and existing institutions on how to guide future transformations $[4,7]$, and have offered criticism of a lack of adequately positioning outcomes of policy support tools in local planning practices [51]. Despite such insights, we did not include a more participatory outlook into our study. The main reason for going through all the steps in a fairly technical and somewhat coarse manner was to show what a landscape architecture rationale offers to the quickly growing body of pathways thinking. We therefore only showed the detailed designing for one path, as we wanted to show the overall concept of landscape design based on pathways. Future work should incorporate the role of participatory methods for research-through-designing and might elaborate on other design choices and their fit within local landscapes through a formalized landscape-based assessment. Combining the scenario workshop method [52] with design charrettes [53] as two forms of participatory action research looks to be a promising way to collaboratively query the implications of pathways on landscapes and vice versa. 


\section{Conclusions}

In this paper we argued that it is important to obtain a better understanding of the spatial and landscape design consequences of pathways in general. To offer a spatial translation of pathways, we conducted a landscape analysis of East Boston and combined this with landscape architecture concepts into a research-through-design approach. In this approach we undertook several iterations to design policy actions as particular spatial interventions and assessed them as to their spatial fit and aesthetic appeal while maintaining their contribution to flood risk reduction. We also illustrated a phased process to design for adaptive and sustainable landscapes.

The results of this study indicate that pathways can be spatially translated, demanding landscape informed choices when sequencing different policy actions. We found that spatial design makes landscape consequences of pathways transparent and informs the feasibility of first measures and the feasibility and timing of possible follow-up interventions. Moreover, it gives a place-based understanding of the path dependency in play. We conclude that policy-makers should be cognizant about the spatial implications of pathways and offer directions to enrich the applications of pathways thinking for achieving adaptive and sustainable landscapes.

Author Contributions: N.K. and M.Z. contributed equally to this paper. Conceptualization, N.K., M.Z., P.K. and A.v.d.B.; Investigation, N.K. and M.Z.; Methodology, N.K., M.Z. and A.v.d.B.; Supervision, P.K. and A.v.d.B.; Visualization, N.K.; Writing—original draft, M.Z. and N.K.; Writing—review and editing, M.Z., P.K. and A.v.d.B.

Funding: This research received no external funding.

Acknowledgments: We kindly acknowledge the time and effort from our interviewees in East Boston. We are grateful to the three anonymous reviewers for putting their time and labor into this work.

Conflicts of Interest: The authors declare no conflict of interest.

\section{Appendix A. List of Interviewees}

Interviewee, Function, Organization

1 Academic expert, Local university

2 Senior expert, Local NGO

3 Public official, MA port authority

4 Senior landscape architect, Employers organization

5 Local NGO, Environmental consultant

6 Local NGO, Community organizer

7-11 Residents.

\section{References}

1. Kwakkel, J.H.; Walker, W.E.; Marchau, V.A.W.J. Classifying and communicating uncertainties in model-based policy analysis. Int. J. Technol. Policy Manag. 2010, 10, 299-316. [CrossRef]

2. Van Rhee, G. Handreiking Adaptief Deltamanagement; Stratelligence: Leiden, The Netherlands, 2012.

3. Wise, R.M.; Fazey, I.; Smith, M.S.; Park, S.E.; Eakin, H.C.; van Garderen, E.A.; Campbell, B. Reconceptualising adaptation to climate change as part of pathways of change and response. Glob. Environ. Chang. 2014, 28, 325-336. [CrossRef]

4. Lawrence, J.; Haasnoot, M. What it took to catalyse uptake of dynamic adaptive pathways planning to address climate change uncertainty. Environ. Sci. Policy 2017, 68, 47-57. [CrossRef]

5. Zandvoort, M.; van der Brugge, R.; van der Vlist, M.J.; van den Brink, A. Dealing with uncertainties in collaborative planning: Developing adaptive strategies for the IJsselmeer. J. Environ. Plan. Manag. 2018. [CrossRef]

6. Krakaya, E.; Nuur, C.; Assbring, L. Potential transitions in the iron and steel industry in Sweden: Towards a hydrogen-based future? J. Clean. Prod. 2018, 195, 651-663. [CrossRef] 
7. Murphy, D.J.; Yung, L.; Wyborn, C.; Williams, D.R. Rethinking climate change adaptation and place through a situated pathways framework: A case study from the Big Hole Valley, USA. Landsc. Urban Plan. 2017, 167, 441-450. [CrossRef]

8. Ramm, T.D.; Watson, C.S.; White, C.J. Strategic adaptation pathway planning to manage sea-level rise and changing coastal flood risk. Environ. Sci. Policy 2018, 87, 92-101. [CrossRef]

9. Buurman, J.; Babovic, V. Adaptation Pathways and Real Options Analysis: An approach to deep uncertainty in climate change adaptation policies. Policy Soc. 2016, 35, 137-150. [CrossRef]

10. Gersonius, B.; Ashley, R.; Pathirana, A.; Zevenbergen, C. Climate change uncertainty: Building flexibility into water and flood risk infrastructure. Clim. Chang. 2013, 116, 411-423. [CrossRef]

11. Smet, K. Engineering Options: A Proactive Planning Approach for Aging Water Resource Infrastructure under Uncertainty. Ph.D. Thesis, Harvard University, Cambridge, MA, USA, 2017.

12. Bell, S. Landscape. Pattern, Perception and Process, 2nd ed.; Routledge: London, UK, 2012; ISBN 9781136318900.

13. Van Dijk, T. Imagining future places: How designs co-constitute what is, and thus influence what will be. Plan. Theory 2011, 10, 124-143. [CrossRef]

14. Van den Brink, A.; Bruns, D. Strategies for Enhancing Landscape Architecture Research. Landsc. Res. 2014, 39, 7-20. [CrossRef]

15. Van den Brink, A.; Bruns, D.; Tobi, H.; Bell, S. (Eds.) Research in Landscape Architecture: Methods and Methodology, 1st ed.; Routledge: New York, NY, USA, 2017.

16. Deming, E.M.; Swaffield, S. Landscape Architecture Research, Inquiry, Strategy, Design; John Wiley \& Sons Inc.: Hoboken, NJ, USA, 2011.

17. Skrimizea, E.; Haniotou, H.; Parra, C. On the 'complexity turn' in planning: An adaptive rationale to navigate spaces and times of uncertainty. Plan. Theory 2018. [CrossRef]

18. Reeder, T.; Ranger, N. How Do You Adapt to an Uncertain World: Lessons from the Thames Estuary 2100 Project; World Resources Institute: Washington, DC, USA, 2010.

19. RIZA. Verkenning Oplossingsrichtingen Volkerak Zoommeer; Rijksinstituut voor Integraal Zoetwaterbeheer en Afvalwaterbehandeling: Lelystad, The Netherlands, 2003.

20. Haasnoot, M.; Kwakkel, J.H.; Walker, W.E.; ter Maat, J. Dynamic adaptive policy pathways: A method for crafting robust decisions for a deeply uncertain world. Glob. Environ. Chang. 2013, 23, 485-498. [CrossRef]

21. Rauws, W.S. Why Planning Needs Complexity: Towards an Adaptive Approach for Guiding Urban and Peri-urban Transformations. Ph.D. Thesis, University of Groningen, Groningen, The Netherlands, 2015.

22. Rauws, W.S.; de Roo, G. Adaptive planning: Generating conditions for urban adaptability. Lessons from Dutch organic development strategies. Environ. Plan. B Plan. Des. 2016, 43, 1052-1074. [CrossRef]

23. van Assche, K.; Beunen, R.; Jacobs, J.; Teampau, P. Crossing trails in the marshes: Rigidity and flexibility in the governance of the Danube Delta. J. Environ. Plan. Manag. 2011, 54, 997-1018. [CrossRef]

24. Wilson, P.I. The Politics of Concrete: Institutions, Infrastructure and Water Policy. Soc. Nat. Resour. 2015, 28, $109-115$. [CrossRef]

25. Markard, J. transformation of Infrastructure: Sector characteristics and implications for fundamental change. J. Infrastruct. Syst. 2010, 17, 107-117. [CrossRef]

26. Zandvoort, M. Planning Amid Uncertainty: Adaptiveness for Spatial Interventions in Delta Areas. Ph.D. Thesis, Wageningen University, Wageningen, The Netherlands, 2017.

27. Weaver, C.P.; Lempert, R.J.; Brown, C.; Hall, J.A.; Revell, D.; Sarewitz, D. Improving the contribution of climate model information to decision making: The value and demands of robust decision frameworks. Wiley Interdiscip. Rev. Clim. Chang. 2013, 4, 39-60. [CrossRef]

28. Wang, T.; de Neufville, R. Building real options into physical systems with stochastic mixed-integer programming. In Proceedings of the 8th Real Options Annual International Conference, Montreal, CA, USA, 7-19 June 2004.

29. Portugali, J.; Meyer, H.; Stolk, E.; Tan, E. (Eds.) Complexity Theories of Cities Have Come Of age: An Overview with Implications to Urban Planning and Design; Springer Science \& Business Media: Heidelberg, Germany, 2012.

30. Innes, J.E.; Booher, D.E. Planning with Complexity: An Introduction to Collaborative Rationality for Public Policy; Routledge: London, UK, 2010.

31. Moroni, S. Complexity and the inherent limits of explanation and prediction: Urban codes for self-organizing cities. Plan. Theory 2015, 14, 248-267. [CrossRef] 
32. Stremke, S.; van Kann, F.; Koh, J. Integrated Visions (Part I): Methodological Framework for Long-term Regional Design. Eur. Plan. Stud. 2012, 20, 305-319. [CrossRef]

33. Ray, P.A.; Brown, C.M. Confronting Climate Uncertainty in Water Resources Planning and Project Design: The Decision Tree Framework; World Bank Publications: Washington, DC, USA, 2015.

34. Lenzholzer, S.; Duchhart, I.; Koh, J. 'Research through designing' in landscape architecture. Landsc. Urban Plan. 2013, 113, 120-127. [CrossRef]

35. Abbott, M. Placing Design, and Designing Place, in Landscape Architecture Research. Landsc. Rev. 2018, $18,89-107$.

36. Farthing, S. Research Design in Urban Planning; Sage Publications Ltd.: London, UK, 2016; ISBN 9781446294444.

37. Thomas, G. The case: Generalisation, theory and phronesis in case study. Oxf. Rev. Educ. 2011, 37, 21-35. [CrossRef]

38. Hallegatte, S.; Green, C.; Nicholls, R.J.; Corfee-Morlot, J. Future flood losses in major coastal cities. Nat. Clim. Chang. 2013, 3, 802-806. [CrossRef]

39. Douglas, E.; Kirshen, P.; Paolisso, M.; Watson, C.; Wiggin, J.; Enrici, A.; Ruth, M. Coastal Flooding, Climate Change, and Environmental Justice: Identifying Obstacles and Incentives for Adaptation in Two Metropolitan Boston Communities. Mitig. Adapt. Strateg. Glob. Chang. 2012, 17, 537-562. [CrossRef]

40. Kuhl, L.; Kirshen, P.; Ruth, M.; Douglas, E. Evacuation as a Climate Adaptation Strategy for Environmental Justice Communities. Clim. Chang. 2014, 127, 493-504. [CrossRef]

41. Kirshen, P.; Ballestero, T.; Douglas, E.; Hesed, C.; Ruth, M.; Paolisso, M.; Watson, C.; Giffee, P.; Vermeer, K.; Bosma, K. Engaging Vulnerable Populations in Multi-Level Stakeholder Collaborative Urban Adaptation Planning for Extreme Events and Climate Risks—A Case Study of East Boston USA. J. Extrem. Events 2018. [CrossRef]

42. Francis, M. A case study method for landscape architecture. Landsc. J. 2001, 20, 15-29. [CrossRef]

43. City of Boston. Climate Ready Boston: Final Report; City of Boston Mayor's Office: Boston, MA, USA, 2016.

44. Kwadijk, J.C.; Haasnoot, M.; Mulder, J.P.; Hoogvliet, M.; Jeuken, A.; van der Krogt, R.A.; de Wit, M.J. Using adaptation tipping points to prepare for climate change and sea level rise: A case study in the Netherlands. Wiley Interdiscip. Rev. Clim. Chang. 2010, 1, 729-740. [CrossRef]

45. Cortesão, J.; Lenzholzer, S.; Klok, L.; Jacobs, C.; Kluck, J. Creating prototypes for cooling urban water bodies. In Proceedings of the 2017 ECLAS Conference, London, UK, 10-13 September 2017; pp. 349-364.

46. BRAG. Climate Change and Sea Level Rise Projections for Boston; City of Boston: Boston, MA, USA, 2016.

47. Kirshen, P.; Knee, K.; Ruth, M. Climate change and coastal flooding in Metro Boston: Impacts and adaptation strategies. Clim. Chang. 2008, 90, 453-473. [CrossRef]

48. Holmes, R.R., Jr.; Dinicola, K. 100-Year flood-it's all about chance. In US Geological Survey Information Product No. 106; US Geological Survey: Reston, VA, USA, 2010.

49. Dronkers, J.; Gilbert, J.T.E.; Butler, L.W.; Carey, J.J.; Campbel, J.; James, E.; McKenzie, C.; Misdorp, R.; Quin, N.; Ries, K.L.; et al. Strategies for Adaptation to Sea Level Rise; Report of the IPCC CZMS; IPCC: Geneva, Switzerland, 1990.

50. EEA. Adaptation in Europe: Addressing Risks and Opportunities from Climate Change in the Context of Socio-Economic Developments (No. 3/2013); Publications Office of the European Union: Luxembourg, 2013.

51. Zandvoort, M.; Campos, I.S.; Vizinho, A.; Penha-Lopes, G.; Lorencová, E.K.; van der Brugge, R.; van der Vlist, M.J.; van den Brink, A.; Jeuken, A.B.M. Adaptation pathways in planning for uncertain climate change: Applications in Portugal, the Czech Republic and the Netherlands. Environ. Sci. Policy 2017, 78, 18-26. [CrossRef]

52. Campos, I.S.; Alves, F.M.; Dinis, J.; Truninger, M.; Vizinho, A.; Penha-Lopes, G. Climate adaptation, transitions, and socially innovative action-research approaches. Ecol. Soc. 2016, 21, 13. [CrossRef]

53. Howard, Z.; Somerville, M.M. A comparative study of two design charrettes: Implications for codesign and participatory action research. Codes. Int. J. Cocreation Des. Arts 2014, 10, 46-62. [CrossRef]

(C) 2019 by the authors. Licensee MDPI, Basel, Switzerland. This article is an open access article distributed under the terms and conditions of the Creative Commons Attribution (CC BY) license (http://creativecommons.org/licenses/by/4.0/). 